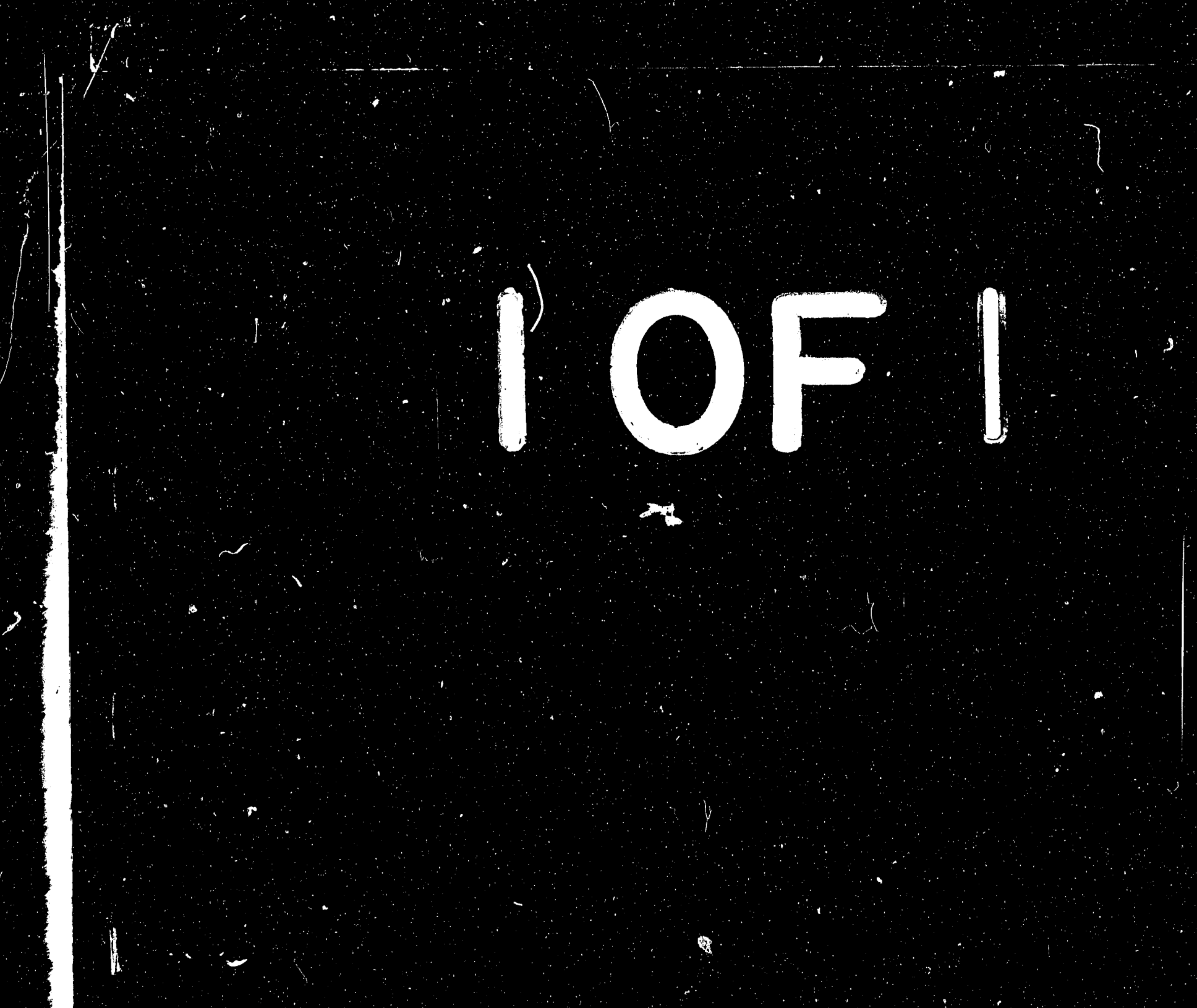


NIPER-563

(DE92001032)

Alkaline Flooding Injection Strategy

By

Troy R. French

Charles B. Josephson

March 1992

Performed Under Cuoperative Agreement No. DE-FC22-83FE60149

IIT Research Institute

National Institute for Petroleum and Energy Research

Bartlesville, Oklahoma

\section{Bartlesville Project Office \\ U. S. CEPARTMENT OF ENERGY \\ Bartlesville, Oklahoma}




\section{DISCLAIMER}

This report was prepared as an account of work sponsored by an agency of the United States Government. Neither the United States Government nor any agency thereof, nor any of their employees, makes any warranty, express or implied or assumes any legal liability or responsibility for the accuracy, cc npleteness, or usefulness of any information, apparatus, product, or process disclosed, or represents that its use would not infringe privately owned rights. Reference herein to any specific commercial product process, or service by trade name, trademark, manufacturer, or otherwise does not necessarily constitute or imply its endorsement, recommendation, or favoring by the United States Government or any agency thereof. The views and opinions of authors expressed herein do not necessarily state or reffect those of the United States Government or any agency thereof

This report has been reproduced directly from the best available copy.

Available to DOE and DOE contractors from the Office of Scientific and Technical Information, P.O. Box 62, Oak Ridge, TN 37831; prices available from (615)576-8401, FTS 626-8401.

Available to the public from the National Technical Information Service, U.S. Department of Commerce, 5285 Port Royal Rd., Springfield, VA 22161. 
NIPER-563

Distribution Category UC-122

\title{
ALKALINE FLOODING INJECTION STRATEGY
}

\author{
Topical Report
}

NIPER--563

DE92 001032

By

Troy R. French

Charles B. Josephson

March 1992

Work Performed Under Cooperative Agreement No. FC22-83FE60149

Prepared for

U.S. Department of Energy

Assistant Secretary for Fossil Energy

Thomas B. Reid, Project Manager

Bartlesville Project Office

P. O. Box 1398

Bartlesville, OK 74005

\author{
Prepared by \\ IIT Research Institute \\ National Institute for Petroleum and Energy Research \\ P. O. Box 2128 \\ Bartlesville, OK 74005
}

MASTER

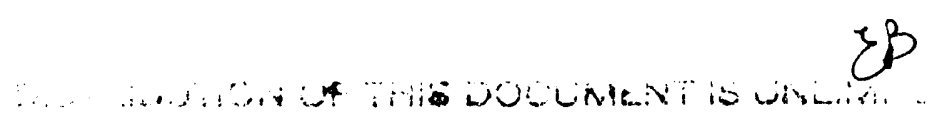




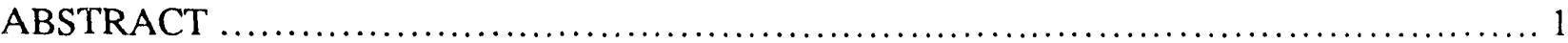



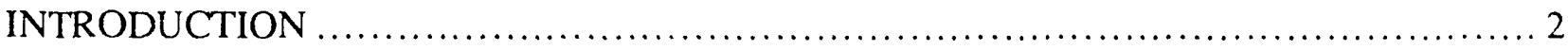

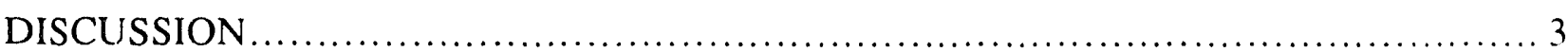

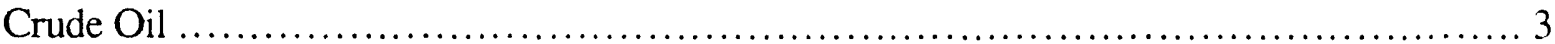

Chemicals and Procedures.......................................................... 3

Effects of Alkaline Chemicals and Surfactants on Oil Recovery ........................ 4

Effect of Polymer Injection Strategy on Oil Recovery ............................... 6

Effects of Alkaline Preflush on Oil Recovery ..................................... 7

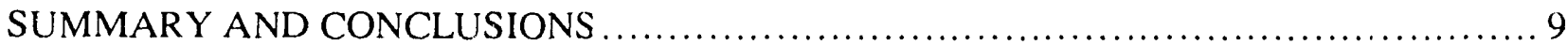



APPENDIX A - COREFLOOD EFFLUENT ANALYSES .................................... 19

TABLE

1. Summary of coreflood injection strategies and results.......................... 12

\section{ILLUSTRATIONS}

1. Dynamic IFT between Hepler (KS) oil and several mixtures of Petrostep B-105 and Petrostep B-1 10 surfactants, $0.095 \mathrm{~N} \mathrm{NaHCO}_{3}, 0.095 \mathrm{~N} \mathrm{Na}_{2} \mathrm{CO}_{3}$, and $1 \% \mathrm{NaCl}$ $\mathrm{pH} 9.5,23^{\circ} \mathrm{C}$. (IPA = isopropyl alcohol and SEC BA = secondary butyl alcohol.) ........14

2. Dynamic IFT between $0.25 \%$ Petrostep B-110 + $0.15 \%$ Petrostep B- 105 and Hepler

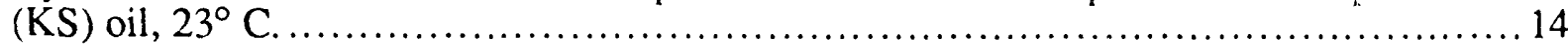

3. Interfacial tension between Hepler (KS) oil and optimized surfactant systems, $23^{\circ} \mathrm{C} \ldots \ldots 15$

4. Recovery of Hepler (KS) crude oil with optimized surfactant systems, $23^{\circ} \mathrm{C} \ldots \ldots \ldots \ldots \ldots 15$

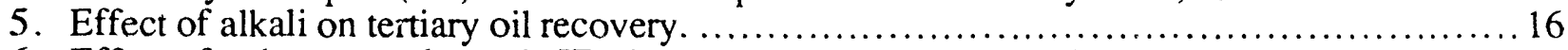

6. Effect of polymer on dynamic IFT between Hepler (KS) oil and a chemical formulation composed of $0.25 \%$ Petrostep B-110, 0.15\% B-105, $0.095 \mathrm{~N} \mathrm{NaHCO}_{3}$,

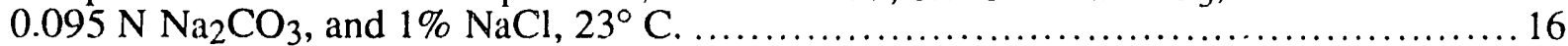

7. Effect of injection strategies on oil production rate ........................................ 17

8. Relationship between oil recovery (waterflood and chemical flood) and alkaline preflush volume............................................................. 17

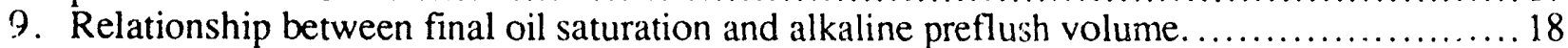

10. Oil recovery for corefloods conducted with $0.25 \mathrm{PV}$ alkaline preflush. ................... 18 


\section{TABLE OF CONTENTS--Continued}

Page

\section{ILLUSTRATIONS}

A-1. Coreflood RP-2 oil saturation and effluent oil cut................................... 19

A-2. Coreflood RP-2 effluent viscosity and surfactant analysis.......................... 19

A -3. Coreflood RP-2 effluent alkalinity and surfactant analysis.........................20

A-4. Coreflood RP-3 oil saturation and effluent oil cut................................ 20

A-5. Coreflood RP-6 oil saturation and effluent oil cut.................................. 21

A-6. Coreflood RP-6 effluent viscosity and surfactant analysis............................ 21

A-7. Coreflood RP-7 oil saturation, effluent oil cut, and surfactant analysis. ................ 22

A-8. Coreflood RP-9 oil saturation and effluent oil cut................................ 22

A-9. Coreflood RP-10 oil saturation and effluent oil cut. ............................... 23

A-10. Coreflood RP-11 oil saturation and effluent oil cut. ................................ 23

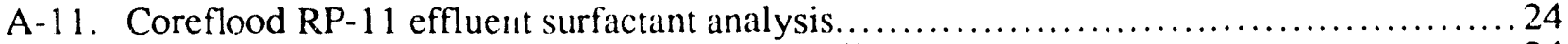

A-12. Coreflood RP-12 oil saturation and effluent oil cut. ............................... 24

A-13. Coreflood RP-12 effluent surfactant analysis .................................... 25

A-14. Coreflood RP-15 oil saturation and effluent oil cut. ................................. 25

A-15. Coreflood RP-15 effluent viscosity and surfactant analysis................................2. 26

A-16. Coreflood RP-17 oil saturation and effluent oil cut. ............................... 26

A-17. Coreflood RP-17 effluent viscosity and surfactant analysis................................. 27 


\title{
ALKALINE FLOODING INJECTION STRATEGY
}

\author{
by Troy R. French and Charles B. Josephson
}

\begin{abstract}
The objective of this project is to develop improved alkali-surfactant flooding methods, and this includes determining the proper design of injection strategy. Several different injection strategies have been used or suggested for recovering heavy oils with surfactant-enhanced alkaline flooding methods.
\end{abstract}

Oil recovery was compared for four different injection strategies: (1) surfactant followed by polymer, (2) surfactant followed by alkaline polymer, (3) alkaline surfactant followed by polymer, and (4) alkali, surfactant, and polymer mixed in a single formulation. The effect of alkaline preflush was also studied under two different conditions.

All of the oil recovery experiments were conducted under optimal conditions with a viscous, non-acidic oil from Hepler (KS) oil field. The coreflood experiments were conducted with Berea sandstone cores since field core was not available in sufficient quantity for coreflood tests. The Tucker sand of Hepler field is a Class I fluvial dominated deltaic reservoir, as classified by the Department of Energy, which has been selected as the site of a DOE-sponsored field pilot test.

The observations from oil recovery tests were as follows:

1. Oil recovery was highest when an alkaline surfactant slug was followed by polymer.

2. Oil recovery decreased only slightly when alkali, surfactant, and polymer were simultaneously injected (mixed in a single slug), and oil production occurred faster.

3. Oil recovery was significantly reduced when surfactant was followed with alkaline polymer.

4. Oil recovery was lowest when surfactant was followed by polymer and no alkali was in any of the injected solutions.

When different volumes of alkaline preflush were injected before injection of the main chemical slug, the following results were noted:

1. Oil production increased as the preflush volume was increased from 0 to $0.25 \mathrm{PV}$. 
2. The alkaline preflush increased oil production in all cases, but the effect was most pronounced when the cores were sattrated with brine that contained divalent ions.

The primary conclusion resulting from this work (which was accomplished with Berea sandstone cores; pertinent to application of surfactant-enhanced alkaline flooding in Hepler field is that alkali, surfactant, and polymer should be injected as a single slug that is preceded by injection of at least $0.1 \mathrm{PV}$ of alkaline preflush. This conclusion needs to verified with field core.

\section{BACKGROUND}

The favorable effect of alkaline chemicals on mobilization of heavy crude oil was discovered in the early part of this century: however, field applications have generally been unsuccessful. The major reason for poor field performance is the high reactivity of strong alkalis with reservoir rock, leading to chemical consumption and the formation of silicate scales at production wells.

The combination of surfactants and weak alkalis for recovery of crude oil is a more recent discovery that has been reported in several publications. ${ }^{1-4}$ With some crude oils, the addition of small concentrations of synthetic surfactant to weak alkaline solutions significantly improves the IFT behavior and increases the mobilization of additional oil. This combination of surfactant and weak alkali also alleviates some of the problems associated with the use of either surfactant alone or alkali alone. Alkali has been shown to reduce the amount of surfactant adsorbed onto reservoir rock, and the use of low concentrations of synthetic surfactants markedly improves the economics of the process. This process is, however, not yet a commercial scale reality.

\section{INTRODUCTION}

In favorable cases, the combination of weak alkalis and surfactants reduces chemical requirements, suppresses scale formation, and increases displacement efficiency. Several mechanisms are involved that are only partially understood. These consist of both equilibrium and dynamic effects. The former includes interfacial activity, adsorption, and ionic equilibria (precipitation and complex formation) and are addressed by the design of the injected formulation. The latter includes chromatographic effects, mobility control, flow diversion by precipitates, and emulsification, and are addressed by injection strategy.

Several injection strategies have been used or suggested. ${ }^{5-8}$ Some examples are as follows: (1) the combination of alkali, surfactant, and polymer into a single slug followed by more polymer, (2) the combination of alkali and surfactant into a single slug, followed by polymer, (3) pre- 
injection of alkali to condition the reservoir, (4) surfactant followed by alkaline polymer, (5) injection of oil soluble acids followed by alkali, and (6) various injection strategies that utilize surfactant and salinity gradients.

The objective of this project is to develop cost-effective and efficient chemical flooding formulations that utilize surfactant-enhanced, weakly alkaline systems. The specific goal for FY91 is to compare injection strategies that can be used for surfactant-enhanced ainaline flooding. This research will also support the design of a planned surfactant-enhanced alkaline flooding field pilot test. ${ }^{9}$ Therefore, the crude oil used for the experiments is from the most likely site for the pilot test.

\section{DISCUSSION}

\section{Crude Oil}

For surfactant-enhanced alkaline flooding, injection strategy is an aspect of optimization that needs to be addressed. Tests were performed with crude oil from the Tucker sand of Hepler field, a DOE Class I, fluvial dominated deltaic reservoir. Oil from Hepler field is viscous. The viscosity of the oil was measured in this laboratory to be $55 \mathrm{cP}$ at $23^{\circ} \mathrm{C}$, which is slightly above reservoir temperature. A different sample of oil analyzed by another laboratory was previously reported to have a viscosity of $76 \mathrm{cP}$. The oil is non-acidic; the total acid number (TAN) is essentially zero.

\section{Chemicals and Procedures}

The chemical systems tested were composed of Petrostep B-110 surfactant, Petrostep B-105 surfactant, $\mathrm{NaHCO}_{3}, \mathrm{Na}_{2} \mathrm{CO}_{3}, \mathrm{NaCl}$, and Flucon $4800-\mathrm{CX}$ biopolymer. The chemical systems were optimized to produce the lowest possible IFT values, which were measured with a University of Texas spinning drop interfacial tensiometer. The addition of 2-butanol to optimized systems reduced turbidity. Some of the optimized systems that were tested did not contain $\mathrm{NaHCO}_{3}$ or $\mathrm{Na}_{2} \mathrm{CO}_{3}$.

Several injection strategies with these chemical systems were tested in laboratory corefloods. The corefloods were conducted with unfired Berea sandstones cores, which were placed in Hassler type coreholders. The cores were first brine saturated. Two synthetic brines were used. All of the cores were saturated with a brine that contained $1.02 \mathrm{~g} \mathrm{NaCl}+0.0388 \mathrm{~g} \mathrm{CaCl}_{2}+0.0694 \mathrm{~g}$ $\mathrm{MgCl}_{2} .6 \mathrm{H}_{2} \mathrm{O} / 100 \mathrm{~mL}$, except cores RP-11, 12, and 15, which were saturated with a brine that contained $1.02 \mathrm{~g} \mathrm{NaCl} / 100 \mathrm{~mL}$ (see table 1). After saturation with brine, permeability to brine was measured. The cores were then oil flooded to residual water saturation, and then waterflooded to residual oil saturation. Chemical flooding was begun after waterflooding to residual water 
saturation. Where possible, the same total amounts of each chemical and the same size chemical slugs were used in the different corefloods. This information is given in table 1 for each coreflood. The use of the same size chemical slugs and same amounts of chemicals facilitates the comparison of the results of corefloods conducted with different injection strategies. Frontal advance rates, based on porosity, were maintained at approximately $1 \mathrm{ft} / \mathrm{d}$.

\section{Effects of Alkaline Chemicals and Surfactants on Oil Recovery}

The following experiments were conducted to compare injection strategies with a surfactant system that was optimized under alkaline conditions. The results under alkaline conditions were compared with a similar system that was optimized without the addition of alkaline agents. Both systems contained the same surfactants and, conveniently, both systems had IFT behaviors that were favorable for mobilization of the selected crude oil. In both instances, the surfactant-containing chemical slug was followed with a separate polymer slug for mobility control.

In another variation of injection strategies, oil recoveries by these two chemical systems were compared to oil recovery when alkali was added to the polymer slug, rather than to the surfactant slug. Yet another injection strategy was to mix polymer, surfactant, and alkali together in a single mixture, and this last mentioned strategy is described later in the section of this report about polymer injection strategy.

The dynamic IFT between Hepler oil and a chemical system containing $0.095 \mathrm{~N} \mathrm{NaHCO}_{3}$, $0.095 \mathrm{~N} \mathrm{Na}_{2} \mathrm{CO}_{3}, 1.0 \% \mathrm{NaCl}$, and various ratios of Petrostep $\mathrm{B}-110$ and Petrostep $\mathrm{B}-105$ surfactants is shown in figure 1. Minimum IFT values were achieved with a mixture that contained $0.25 \%$ Petrostep B-110 surfactant mixed with $0.15 \%$ Petrostep B-105 surfactant. The minimum IFT value achieved was about $6 \mu \mathrm{N} / \mathrm{m}$. Values below $10 \mu \mathrm{N} / \mathrm{m}$ have been shown to be favorable for the mobilization of significant amounts of residual oil.

Figure 2 shows the dyramic IFT behavior of the same mixture of Petrostep surfactants, but without carbonates present in the chemical system. In this case, the system was optimized for lowest IFT by adjusting the concentration of $\mathrm{NaCl}$ (salinity scan). The optimal salinity (without alkali) was determined, based on overall IFT performance, to be approximately $2.0 \% \mathrm{NaCl}$. This chemical system contained only $0.25 \%$ Petrostep B-110 surfactant, 0.15\% Petrostep B-105 surfactant, and $2.0 \% \mathrm{NaCl}$. Minimum IFT with this chemical system and Hepler oil was about 5 $\mu \mathrm{N} / \mathrm{m}$, which is very nearly equal to the minimum IFT value of $6 \mu \mathrm{N} / \mathrm{m}$ measured for the system described above, which contained alkali. The IFT of both chemical systems is shown in figure 3 . 
The similarity of the IFI behaviors for the two chemical systems is not surprising, since Hepler oil is non-acidic.

Based on the IFT results, it would be expected that the system without alkali would mobilize an amount of oil similar to that mobilized by the chemical system that contains alkali. Actual oil recoveries with the two chemical systems are shown in figure 4. The two coreflood results shown are for corefloods RP-2 and RP-7, which are summarized in table 1. Figure 4 shows the cumulative amount of oil recovered by waterflooding and chemical flooding. Oil recovery from the chemical flood was much higher for the chemical system optimized with alkali in the chemical formulation. Oil recovery $\left(100 \times\left(\mathrm{So}_{w f}-\mathrm{So}_{\mathcal{C}}\right) \div \mathrm{So}_{\mathrm{wf}}\right)$ with the alkali/surfactant chemical system was $85.0 \pm 0.9 \%$ of the oil that remained after waterflood; oil recovery with the non-alkaline surfactant system was $26.4 \%$. The effect on tertiary oil recovery (chemical flood) is also compared in figure 5. These results indicate that, for optimized systems, including alkali in the surfactant system increases oil mobilization even when IFT behavior is not substantially improved.

Appendix A contains figures for the effluent analyses for most of the corefloods shown in table 1. Waterflood results are not shown in the graphs in appendix A. Zero PV on the X-abscissa is the beginning of the chemical flood. Analyses for surfactant in the aqueous effluent from corefloods RP-2 (with alkali, pH 9.5) and RP-7 (no alkali, pH 7.1) are shown in figures A-3 and A-7 and reveal that the percentage of injected surfactant retained in the cores was virtually identical for both corefloods, $78.5 \%$ and $70.8 \%$, respectively. Partition coefficient measurements indicated that very little of the surfactant was solubilized into the oil phase. Thus, even though the presence of alkali in an optimized surfactant formulation substantially increased the amount of Hepler oil recovered, the presence of the alkali did not appear to reduce the amount of surfactant adsorbed.

Another injection strategy was tested. Coreflood RP-17 (table 1) was conducted with alkali and surfactant, but the alkali was injected with the polymer, rather than with the surfactant. The polymer/alkali slug was injected after the surfactant slug. This is similar to an injection strategy described by Schuler. 5 With this strategy, a larger total volume must be injected into porous media before IFT reaches a minimum; however, minimum IFT values between produced fluids were shown to occur over a large effluent pore volume. In this case, oil recovery was $40.1 \%$ of the oil that remained after waterflooding, which is intermediate between the oil recovery with surfactant alone (26.4\% OIP) and alkali contained in the same slug as the surfactant $(85.0 \%$ OIP). This indicates that the synergism between alkali and surfactant is reduced when they are not inixed together in the same slug. Effluent surfactant analysis for coreflood RP-17 is shown in figure A17. Interestingly, the amount of surfactant retained in this core was $75.1 \%$ of the amount injected, which is about the same as for other injection strategies. 


\section{Effect of Polymer Injection Strategy on Oil Recovery}

Hepler oil viscosity is high; therefore, a high concentration of polymer is needed to achieve a favorable mobility ratio. IFT experiments were conducted with alkali, surfactant, and polymer mixtures to separate the effects of the different chemicals on dynamic IFT behavior. Figure 6 shows the effect of polymer on the IFT obtained with the previously mentioned mixture of surfactant and alkali. The effect of polymer was to increase both initial and equilibrium IFT values.

Therefore, based on the spinning drop IFT measurements, injections of a mixture of alkali plus surfactant in one slug and polymer in a separate slug would be expected to produce more incremental oil than combining alkali, surfactant, and polymer into one slug. This prediction was, however, not substantiated by the corefloods conducted for the purpose of comparing injection strategies.

Table 1 shows that injecting polymer as a part of a chemical slug containing surfactant, alkali, and polymer (coreflood RP-6) produced nearly as much incremental oil as injection of separate surfactant plus alkali and polymer slugs (corefloods RP-2 and RP-3). The combined injection (coreflood RP-6) produced $78.9 \%$ of the oil that remained after waterflooding. This

compares with $85.0 \pm 0.9 \%$ for injection of separate polymer and alkali plus surfactant formulations.

An advantage of including the polymer in the alkali/surfactant slug is shown in figure 7. Tertiary oil production occurred significantly faster in the coreflood (RP-6) conducted with the single slug of alkali plus polymer plus surfactant. Another advantage is that the suriactant and alkali should sweep more of the reservoir when polymer is contained in the same slug as the surfactant and alkali, although this result is not apparent from the results of these linear corefloods.

Some instability (phase separation after prolonged standing) was observed when polymer and surfactant were contained in the same mixture. Examination of the surfactant effluent analyses shown for corefloods RP- 2 and RP-6 in appendix A reveals that the amount of surfactant retention was almost identical for the two corefloods, $78.5 \%$ and $75.0 \%$ of the amount of surfactant injected. This indicates that the observed instability did not result in more surfactant being retained in the core when surfactant and polymer were contained in the same mixture, rather than in separate chemical slugs. 


\section{Effects of Alkaline Preflush on Oil Recovery}

An alkaline preflush is one strategy that has been suggested for increasing oil recovery during chemical flooding. 8,10 Tests were conducted with crude oil from the Tucker sand of Hepler field and the chemical system composed of $0.25 \%$ Petrostep B-110 surfactant, $0.15 \%$ Petrostep B-105 surfactant, $0.095 \mathrm{~N} \mathrm{NaHCO}_{3}, 0.095 \mathrm{~N} \mathrm{Na}_{2} \mathrm{CO}_{3}$, and $1.0 \% \mathrm{NaCl}$ (optimal salinity). Two percent 2-butanol was added to the chemical formulation to reduce turbidity. The alkali/surfactant slug was preceded by injection of variable volumes of a preflush solution that contained $0.095 \mathrm{~N} \mathrm{NaHCO}_{3}$, $0.095 \mathrm{~N} \mathrm{Na}_{2} \mathrm{CO}_{3}$, and $1.0 \% \mathrm{NaCl}$. Mobility control was accomplished by following the preflush and alkali/surfactant injections with $3,500 \mathrm{ppm}$ Flocon $480(0) \mathrm{CX}$ biopolymer in $1.0 \% \mathrm{NaCl}$.

The coreflood experiments were conducted under two conditions. Three Berea cores were saturated with synthetic Hepler brine, flooded with oil to residual brine saturation, and then waterflooded to residual oil saturation with synthetic brine. The synthetic brine contained $1.022 \%$ $\mathrm{NaCl}+0.0388 \% \mathrm{CaCl}_{2}+0.0325 \% \mathrm{MgCl}_{2}$. A similar set of three cores was saturated with $1.022 \% \mathrm{NaCl}$, flooded with oil to residual brine saturation, and waterflooded to residual oil saturation with $1.022 \% \mathrm{NaCl}$. Ionic strengths (IS) of both brines were similar. Ionic strength of synthetic Hepler brine is $0.196 \mathrm{M}$ vs. $0.175 \mathrm{M}$ for $1.022 \% \mathrm{NaCl}$. After waterflooding to residual oil saturation, each core was flooded with an alkaline preflush volume of $0.0,0.1$, or $0.25 \mathrm{PV}$. After preflush, $0.75 \mathrm{PV}$ of the surfactant-enhanced alkaline formulation described above was injected, followed by 1.0 PV polymer.

The Berea cores used for the experiments had widely different permeabilities. Absolute permeabilities of the cores were as low as $517 \mathrm{mD}$ and as high as $994 \mathrm{mD}$. Therefore, coreflood results were interpreted by using a technique that takes into account changes in oil production that can be attributed to using cores that do not have identical permeabilities. Plots of oil recovery verses permeability and oil recovery verses preflush volume were used. Total oil recoveries (waterflood + chemical) for the two sets of corefloods are shown in figure 8. Corefloods RP-2, RP-9, and RP-10 (coreflood data set No. 1) were conducted in cores saturated with synthetic brine. Corefloods RP-11, RP-12, and RP-15 (coreflood data set No. 2) were conducted in cores saturated with $\mathrm{NaCl}$. The linear correlation coefficients $(\mathrm{R})$ for both sets of data are equal to 1.000. Plots of final oil saturation (at the end of chemical flooding) are shown in figure 9. The data contained in figure 9 show exactly the same trends as those shown in figure 8 , but the correlation is slightly lower $(\mathrm{R}=0.988)$. 
The amount of oil produced was shown to increase as preflush volume was increased and as permeability increased (see figure 3 ). Corefloods conducted in the cores saturated with synthetic Heple: brine showed increasing oil recovery as preflush volume was increased. Total oil recovery increased from 74.9 to $93.6 \%$ OOIP $(\Delta=18.7 \%)$. Curve slope was 0.11 . In identical coreflocds conducted after saturation with $1.022 \%, \mathrm{VaCl}$, oil recovery increased (with prefl ${ }_{i}$ sh volume) from 81.8 to $88.7 \%$ OOIP ( $\dot{\Delta}=6.9 \%$ ). Curve slope was 0.01 .

Comparison of the curve slopes indicates that alkaline preflush had a much greater erfect on oil recovery in the corefloods conducted in cores saturated with synthetic Henler brine than in cores saturated with $\mathrm{NaCl}$. The results also indicate that, under these conditions, $0.1 \mathrm{PV}$ of alkaline preflush is sufficient to mitigate the deleterious effects of divalent ions on oil recovery. The concentration of carbonate ions in the preflush formulation was $0.190 \mathrm{~N}$. The concentration of divalent ions in synthetic Hepler brine is $0.0138 \mathrm{~N}$. Although stoichiometry is not equal, it is reasonable that $0.1 \mathrm{PV}$ of alkaline preflush was required to mitigate adverse divalent ion effects because the erfectiveness of the pretlush was probably reduced by fingering through the porous medium. This also indicates that a small amount of viscosity enhancement, to reduce fingering hy providing a more favorable mobility ratio between preflush and brine, will increase preflush effectiveness.

In figure 10, the relationship shown is how oil recovery with this chemical system currelated with permeability for several corefloods conducted with 0.25 PV of alkaline preflush. The graph contains data from corefloods conducted with both synthetic brines described previously and presents a general relationship between oil recovery and permeability that was observed when the volumes of preflush, surfactant-enhanced alkali, and polymer were the same for all corefloods. Figure 10 should be used to further understand the results shown in figure 8 . From figure 10, we can predict, based on core permeability, oil recovery for corefloods conducted with this chemical system and $0.25 \mathrm{PV}$ alkaline preflush volume.

For coreflood data set No. 1 (brine with divalent ions, see table 1), coreflood RP-2 that was conducted with $0.25 \mathrm{PV}$ preflush actually produced a little more il that was predicted from figure 10. Coreflood RP-10 (0.1 PV) produced a little less than predicted. Coreflood RP-9 (no preflush) produced much less oil than was predicted ( $86 \%$ OOIP predicted vs. $75 \%$ actual recovery). As indicated by the steep slope of the curve for this data set. increasing the size of alkaline preflush had a very favorable effect on oil recovery. This is in agreement with the conclusions previously drawn from figure 8. 
For ccreflood data set No. 2 (no divalents), oil recovery at any given permeability is nearly the same as that predicted from figure 10. This indicates that without divalent ions present, alkaline preflush volume has but little effect on oil recovery. Therefor, the effectiveness of alkaline preflush appears to be related to the presence of divalent ions in the reservoir. This is particularly apparent in this case, because Hepler oil is non-acidic (i.e. does not contain species that are reactive v/ith alkali). Alkaline preflush appears io be very effective for increasing oil recovery when divalent ions are present in brine, but much less effective when divalent ions are absent.

A significant fact is that the curves for the two data sets shown in figure 8 come together and then cross-over at about $0.1 \mathrm{PV}$. That this occurs is reflected in the difference between curve slopes. The slope for data set No. 1 is much steeper than for data set No. 2. This behavior is easily understood when one considers what happens during the waterflood portion of an oil recovery coreflood. After waterflooding is complete, channels will have been established in the porous medium due to viscous fingering of the brire through the oil. 11 Precipitation that may occur during the alkaline preflush would redirect the injected chemical formulation into areas of higher oil saturation, and consequently, oil production would be increased.

Figure 9 also shows that with no alkaline preflush, residual oil saturation after chemical flooding was lowest when the brine did not contain divalent ions. The reason for this is not completely apparent, but is probably related to divalent ion - surfactant interactivi. In contrast to this, when $0.25 \mathrm{PV}$ of alkaline preflush was injected before injection of the main surfactant slug, oil saturation after chemical flooding was lowest when divalent ions were present in the brine. This latter observation is consistent with the conclusion stated above. Increased oil production is at least partially due to flow diversion by carbonate precipitation.

\section{SUMMARY AND CONCLUSIONS}

Oil recovery was compared for four different injection strategies: (1) surfactant followed by polymer, (2) surfactant followed by alkaline polymer, (3) alkaline surfactant followed by polymer, and (4) alkali, surfactant, and polymer mixed in a single formulation. The effect of alkaline preflush was also studied under two different conditions.

All of the oil recovery experiments were conducted in Berea sandstone under optimal conditions with a viscous, non-acidic oil from Hepler field. The Tucker sand of Hepler field is a class I, fluvial dominated deltaic reservoir, which is expected to be the site of a DOE-sponsored field pilot test. 
The observations from oil recovery tests were as follows:

1. Oil recovery was highest when alkaline surfactant was followed by polymer.

2. Oil recovery was only slightly decreased $:$ hen the alkali, surfactant, and polymer were simultaneously injected (mixed in single slug), and oil production occurred faster.

3. Oil recovery was significantly reduced when surfactant was followed with alkaline polymer.

4. Oil recovery was lowest when surfactant was followed by poiymer and there was no alkali in any of the injected solutions.

When different alkaline preflush volumes were injected before injection of the main chemical slug, it was observed that:

1. Oil production increased as the preflush volume was increased from 0 to $0.25 \mathrm{PV}$.

2. The alkaline preflush increased oil production in all cases, but the effect was most pronounced when the cores were saturated with brine that contained divalent ions.

The conclusion pertinent to application of surfactant-enhanced alkaline flooding in Hepler field is that alkali, surfactant, and polymer should be injected as a single slug that is preceded by injection of at least $0.1 \mathrm{PV}$ of alkaline preflush. This conclusion needs to be verified with field core.

\section{REFERENCES}

1. French, T. R. and T. E. Burchfield. Design wnd Optimization of Alkaline Flonding Formulations. Pres. at the Seventh Joint SPE/DOE Symposium on Enhanced Oil Recovery Tulsa, OK April 1990, SPE/DOE paper 20238.

2. Cheng, K. H. Chemical Consumption During Alkaline Flooding: A Comparative Evaluation. Pres. at the Fifth Joint SPE/DOE Symposium on Enhanced Oil Recovery, Tulsa, OK, Apr. 20-23, 1986, SPE/DOE paper 14944.

3. Peru, D.A. Aqueous Flooding Methods for Tertiary Oil Recovery. U. S. Patent 4,817,715, April 1989.

4. Nelson, R.C., J.B. Lawson, D.R. Thigpen, and G. L. Stegemeier. Cosurfactant-Enhanced Alkaline Flooding. Pres. at the Fourth Joint SPE/DOE Symposium on Enhanced Oil Recovery, Tulsa, OK, Apr. 16-18, 1984, SPE/DOE paper 12672.

5. Schuler, P. J., R. M. Lerner, and D. L. Kuchne. Improving Chemical Flood Efficiency with Micellar/Alkaline/Polymer Processes. Pres. at the Fifth SPE/DOE Symp. on Enhanced Oil Recovery, Tulsa, OK, Apr. 20-23, 1986. SPE/DOE paper 14934. 
6. Krumrine, P. H., J. S. Falcone, Jr., and T. C. Camphell. Surfactant Flooding 1: The Effect of Alkaline Additives on IFT, Surfactant Adsorption, and Recovery Efficiency. Soc. Pet. Eng. J., v. 22, No. 4, August 1982.

7. Krumrine, P. H. and J. S. Falcone, Jr. Surfactant, Polymer, and Alkali Interactions in Chemical Flooding Processes. Pres. at the SPE Int'I Symp. on Oilfield and Geothermal Chemistry, Denver, CO, June 1-3, 1983, SPE paper 11778.

8. Lorenz, P. B. and D. A Peru. Guidelines Help Select Reservoirs for $\mathrm{NaHCO}_{3}$ EOR. Oil \& Gas J., v. 87, No. 37, Sept. 11, 1989, pp. 53-57.

9. French, Troy R. Design of Chemical Formulation for Project SGP41. Status Report submitted to U. S. Department of Energy, May 1991, Report No. NIPER-530.

10. Labrid, J. and B. Bazin. Alkaline Preflush in a Low-Permeability Clayey Sandstone. J. Pet. Sci. Eng., v. 3, 1989, pp. 111-120.

11. Agharazi-Dormani, N., V. Hornof, and G. H. Neale. Effects of Divalent Ions in Surfactant Flooding. J. Pet. Sci. Eng., v. 4, 1990, pp. 189-196. 


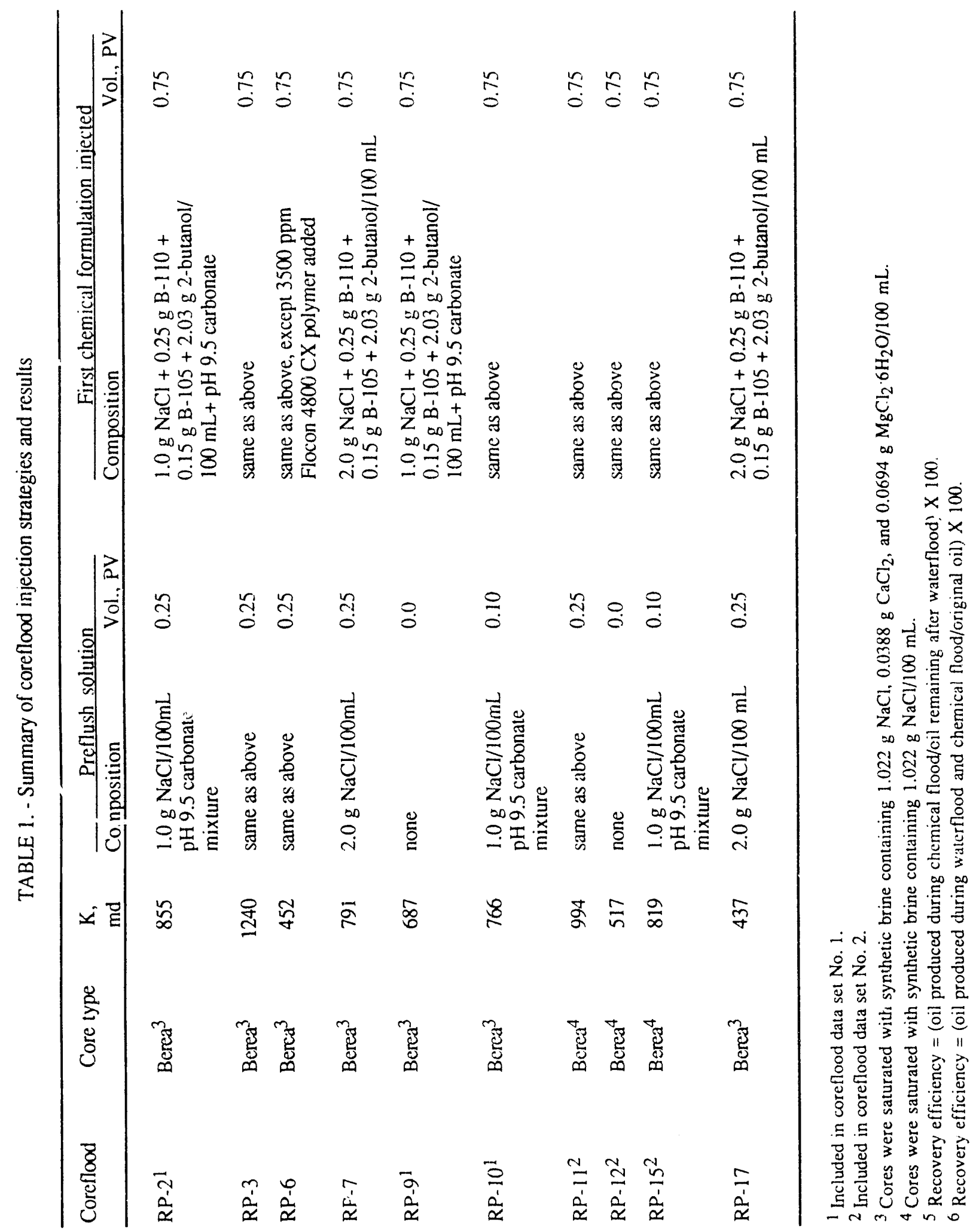




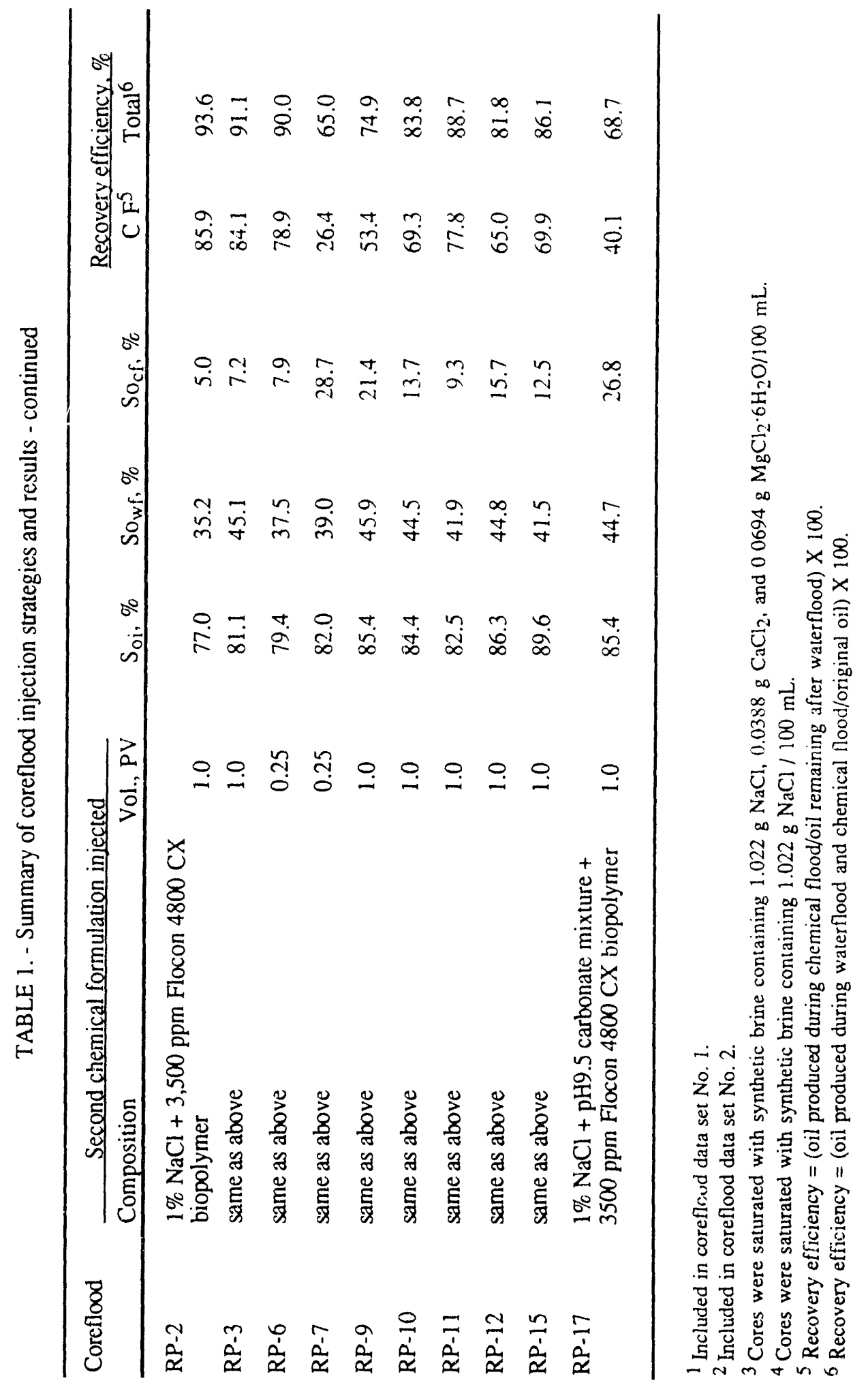




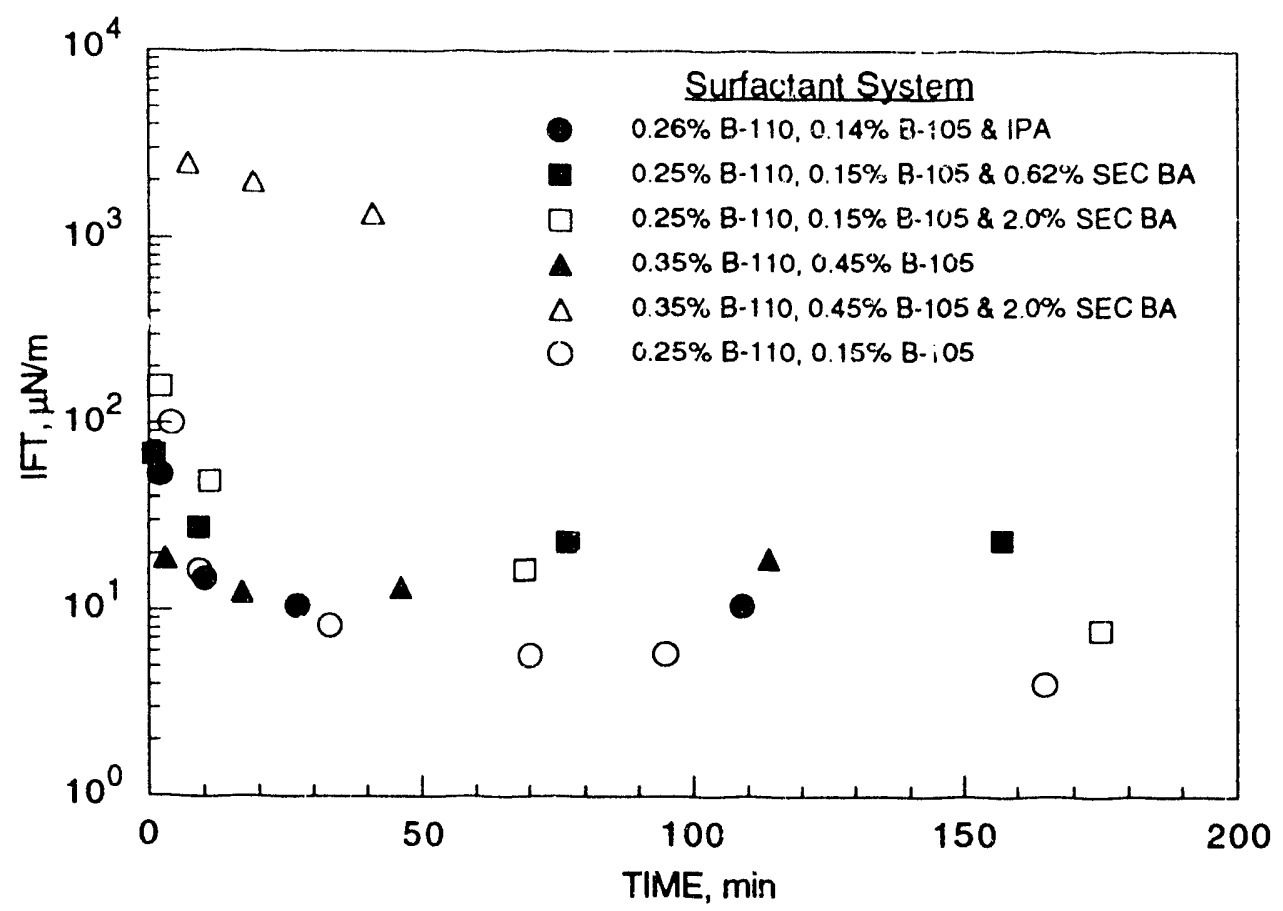

FIGURE 1. - Dynamic IFT between Hepler (KS) nil and several mixtures of Petrostep B-105 and Petrostep B-110 surfactants, 0.095N NaHCO $3,0.095 \mathrm{~N} \mathrm{Na}_{2} \mathrm{CO}_{3}$, and $1 \% \mathrm{NaCl}, \mathrm{pH} 9.5,23^{\circ} \mathrm{C}$. (IPA = isopropyl alcohol and SEC BA = secondary butyl alcohol.)

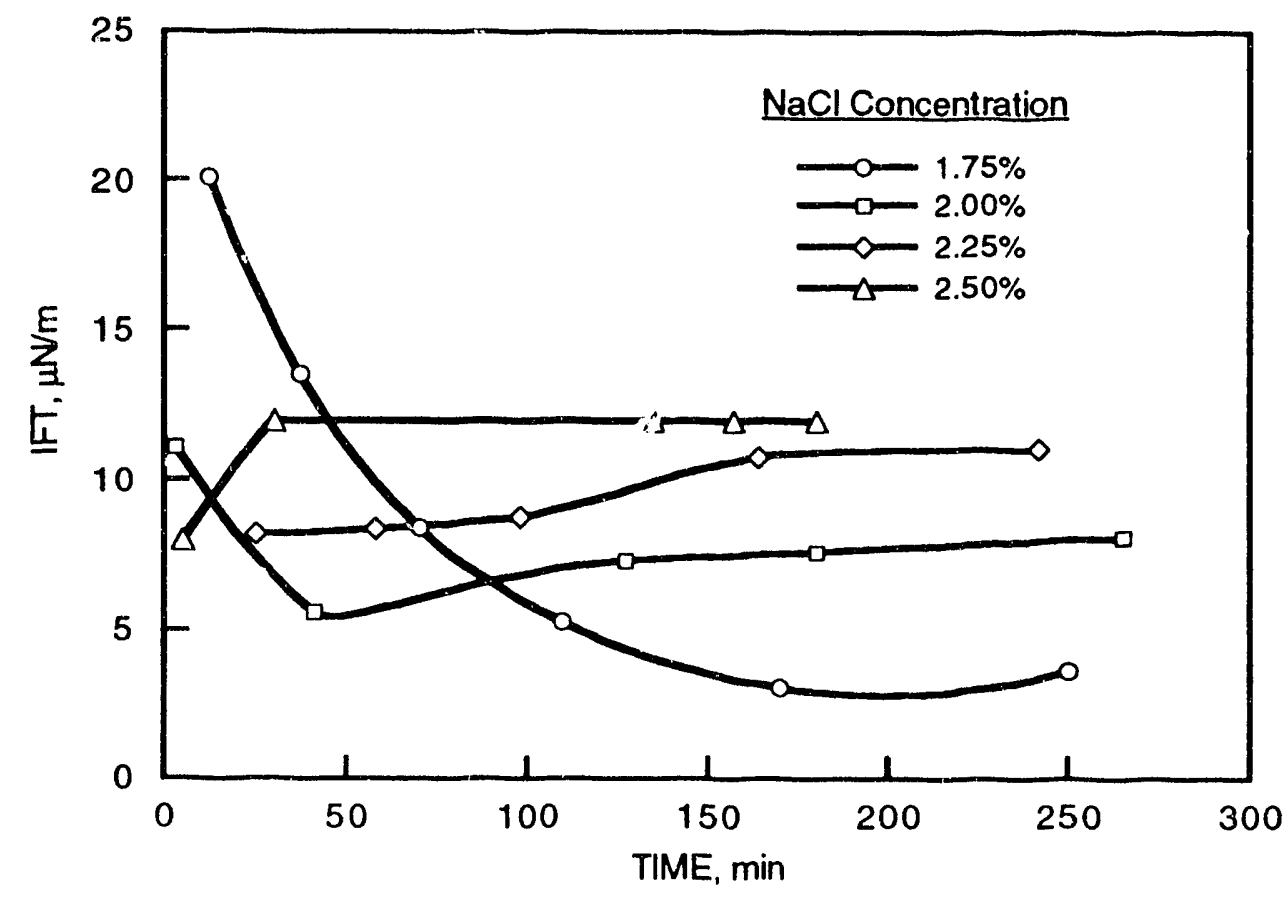

FIGURE 2. - Dynamic IFT between $0.25 \%$ Petrostep B-110 + $0.15 \%$ Petrostep B-105 and Hepler (KS) oil, $23^{\circ} \mathrm{C}$. 


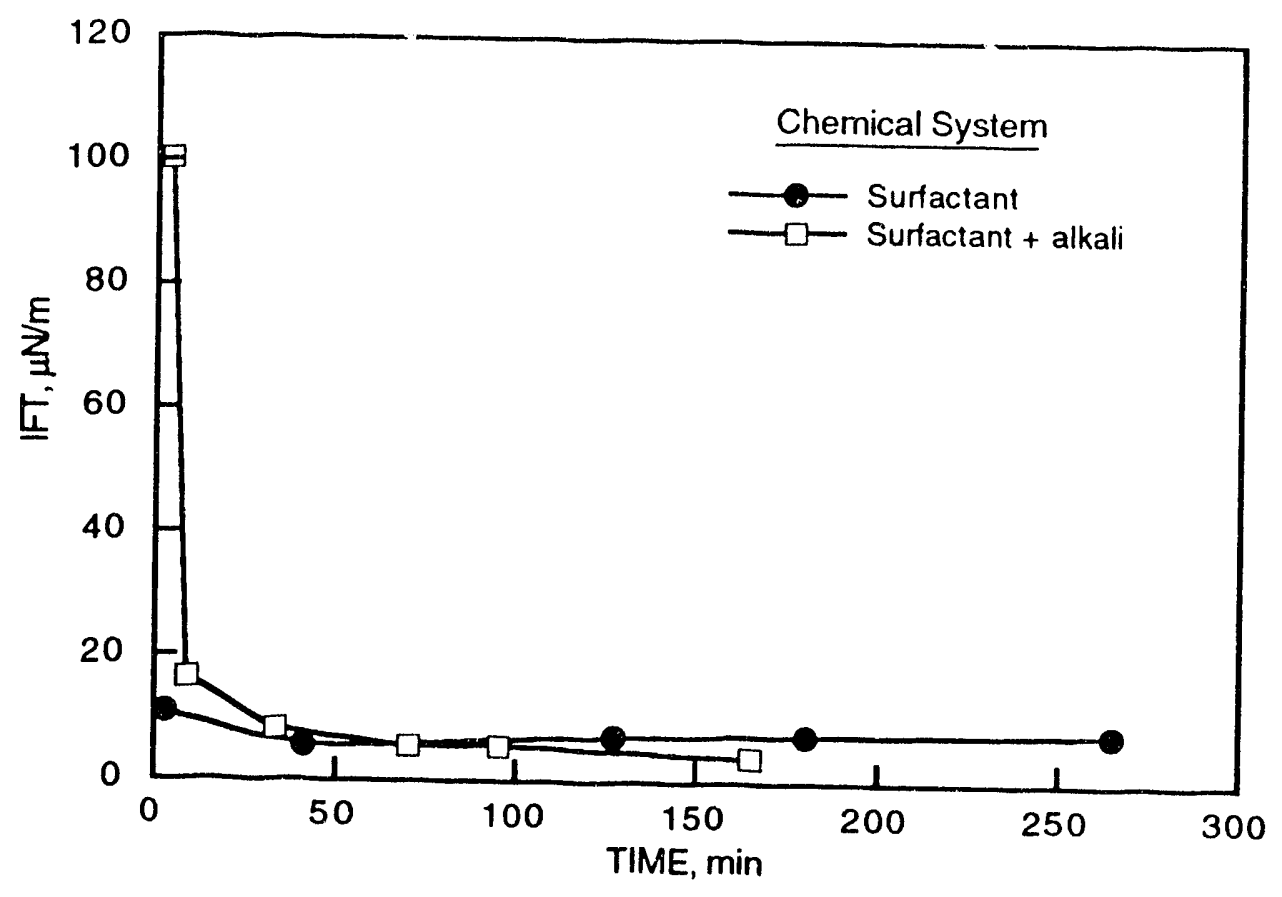

FIGURE 3. - Interfacial tension between Hepler (KS) oil and optimized surfactant systems, $23^{\circ} \mathrm{C}$.

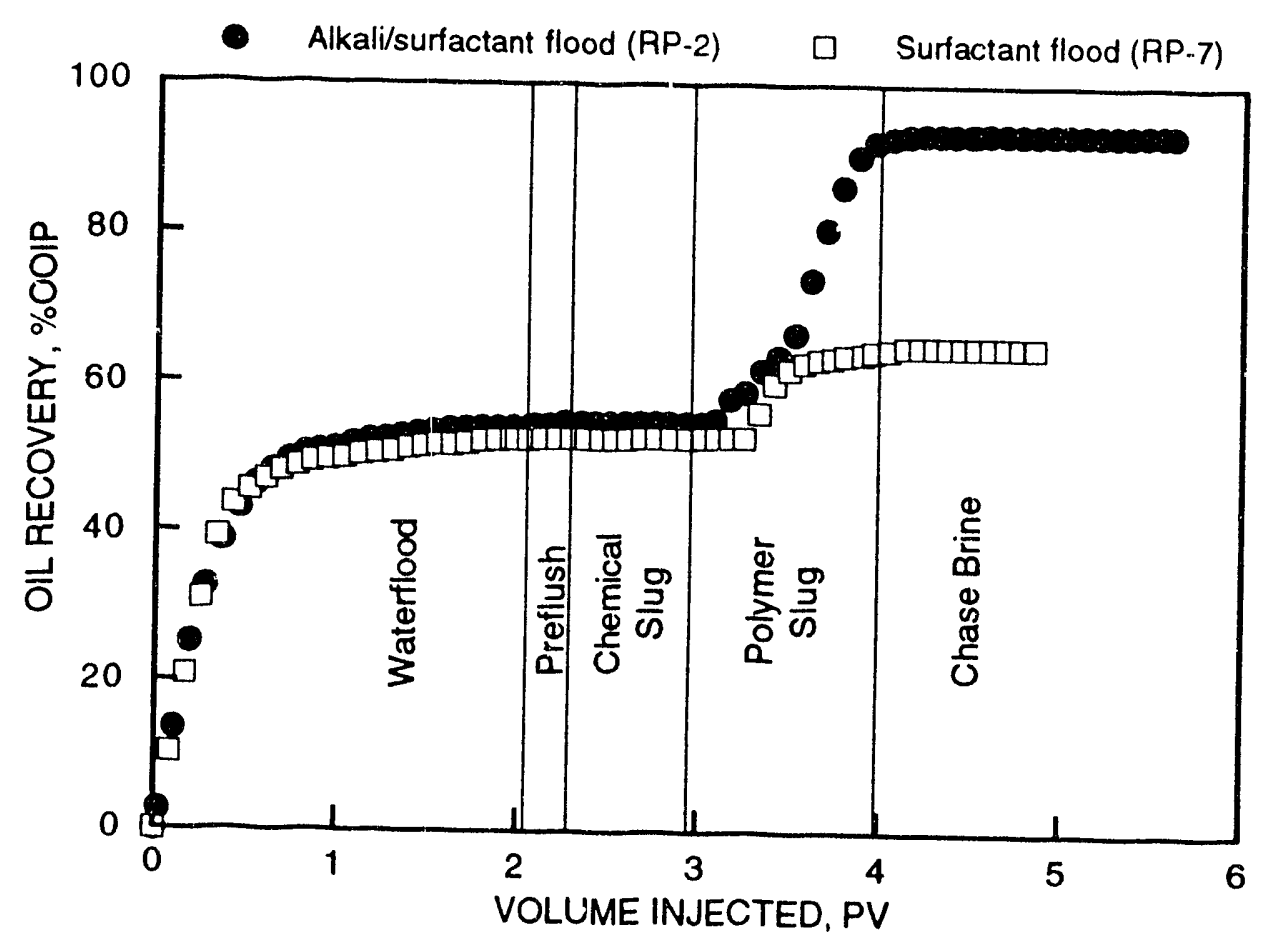

FIGURE 4. - Recovery of Hepler (KS) crude oil with optimized surfactant systems, $23^{\circ} \mathrm{C}$. 


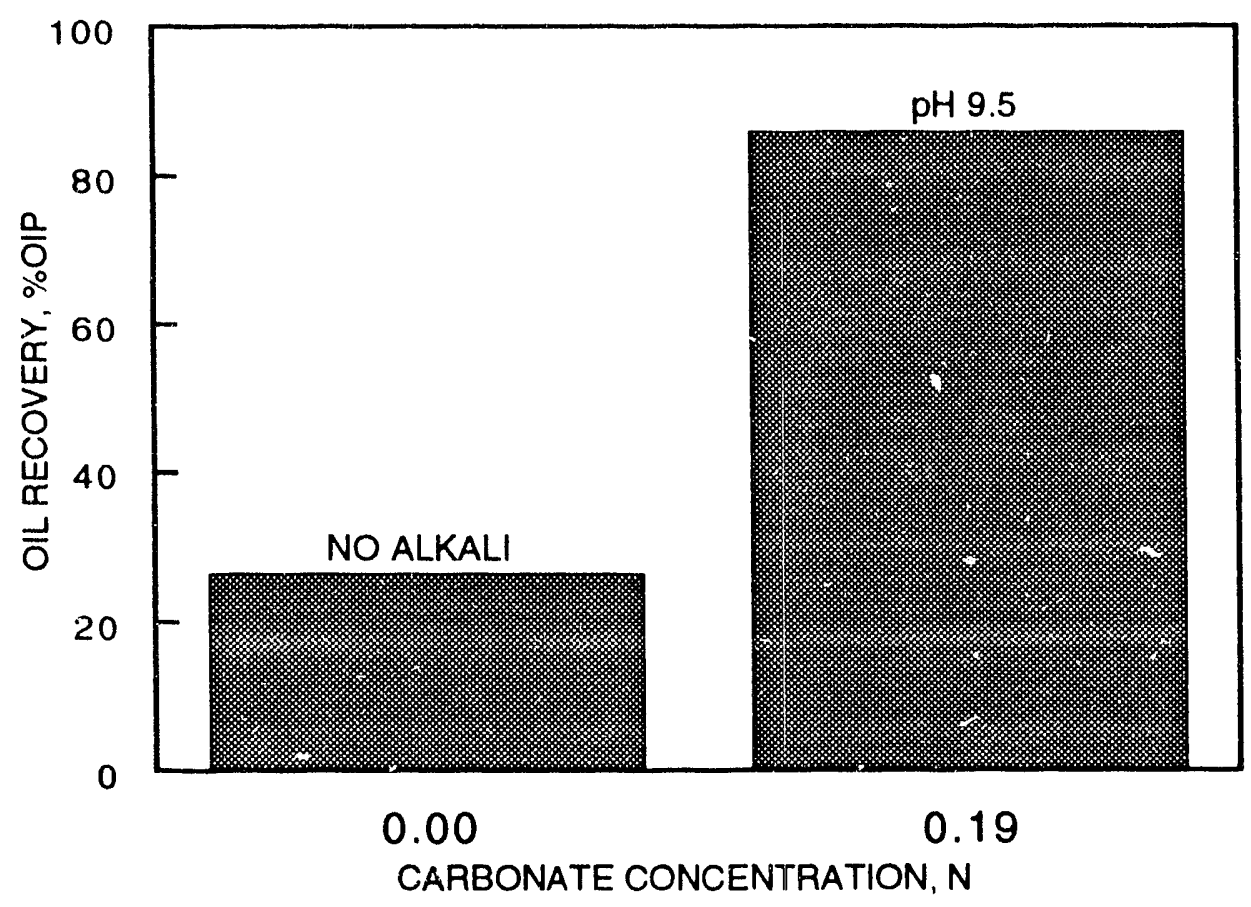

FIGURE 5. - Effect of alkali on tertiary oil recovery.

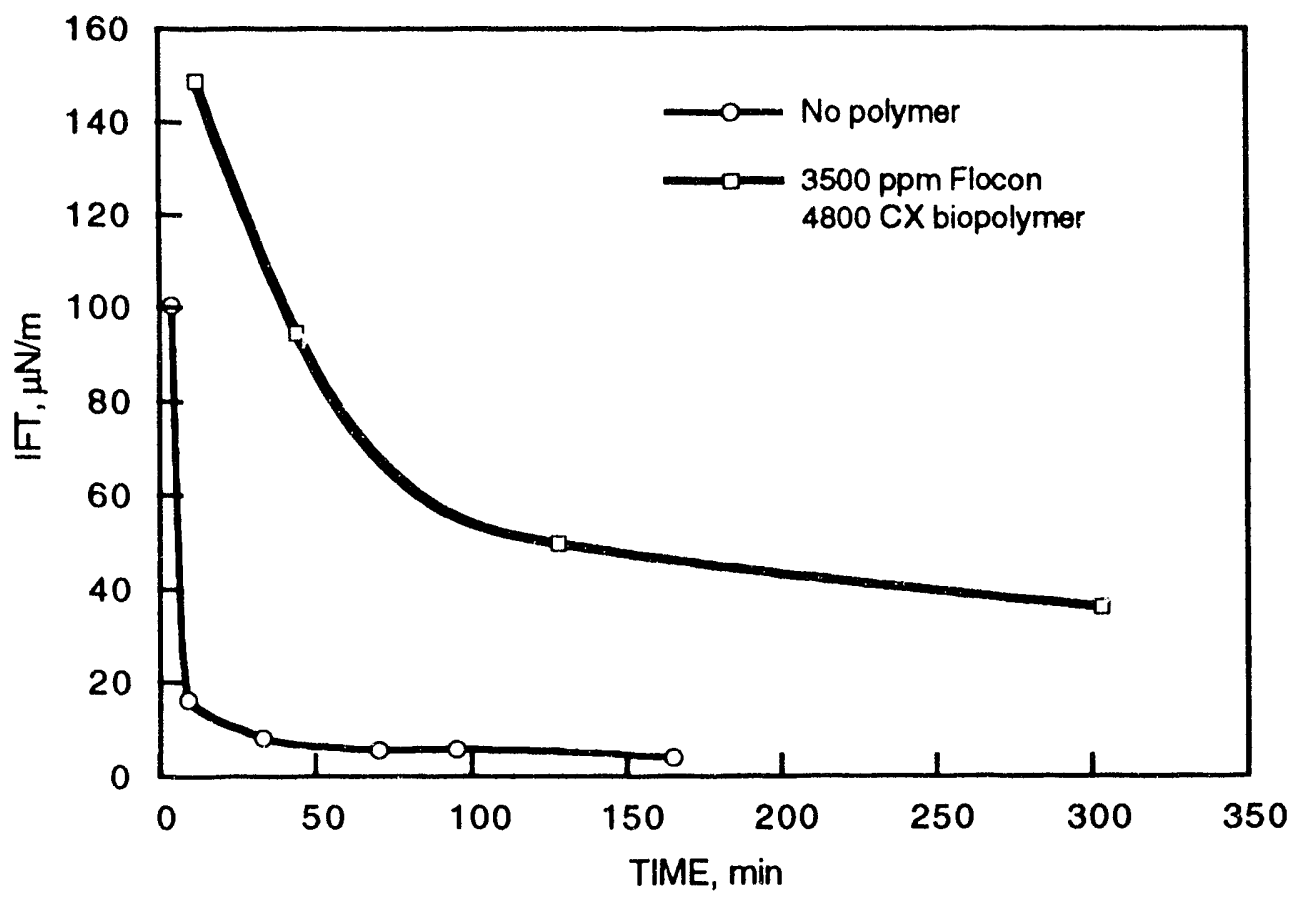

FIGURE 6. - Effect of polymer on dynamic IFT between Hepler (KS) oil and a chemical formulation composed of $0.25 \%$ Petrostep B-110, 0.15\% B-105, $0.095 \mathrm{~N}$ $\mathrm{NaHCO}_{3}, 0.095 \mathrm{~N} \mathrm{Na}_{2} \mathrm{CO}_{3}$, and $1 \% \mathrm{NaCl}, 23^{\circ} \mathrm{C}$. 


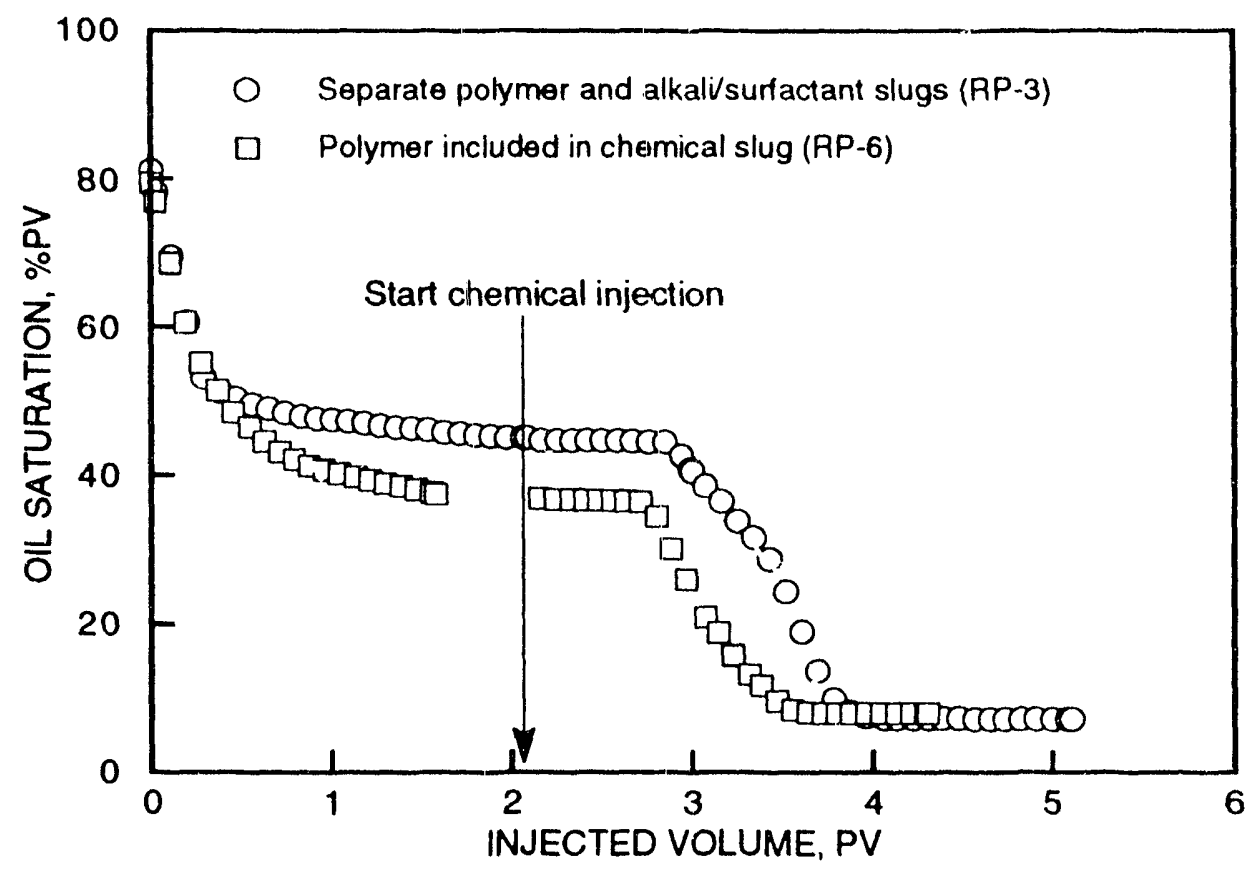

FIGURE 7. - Effect of injection strategies on oil production rate.

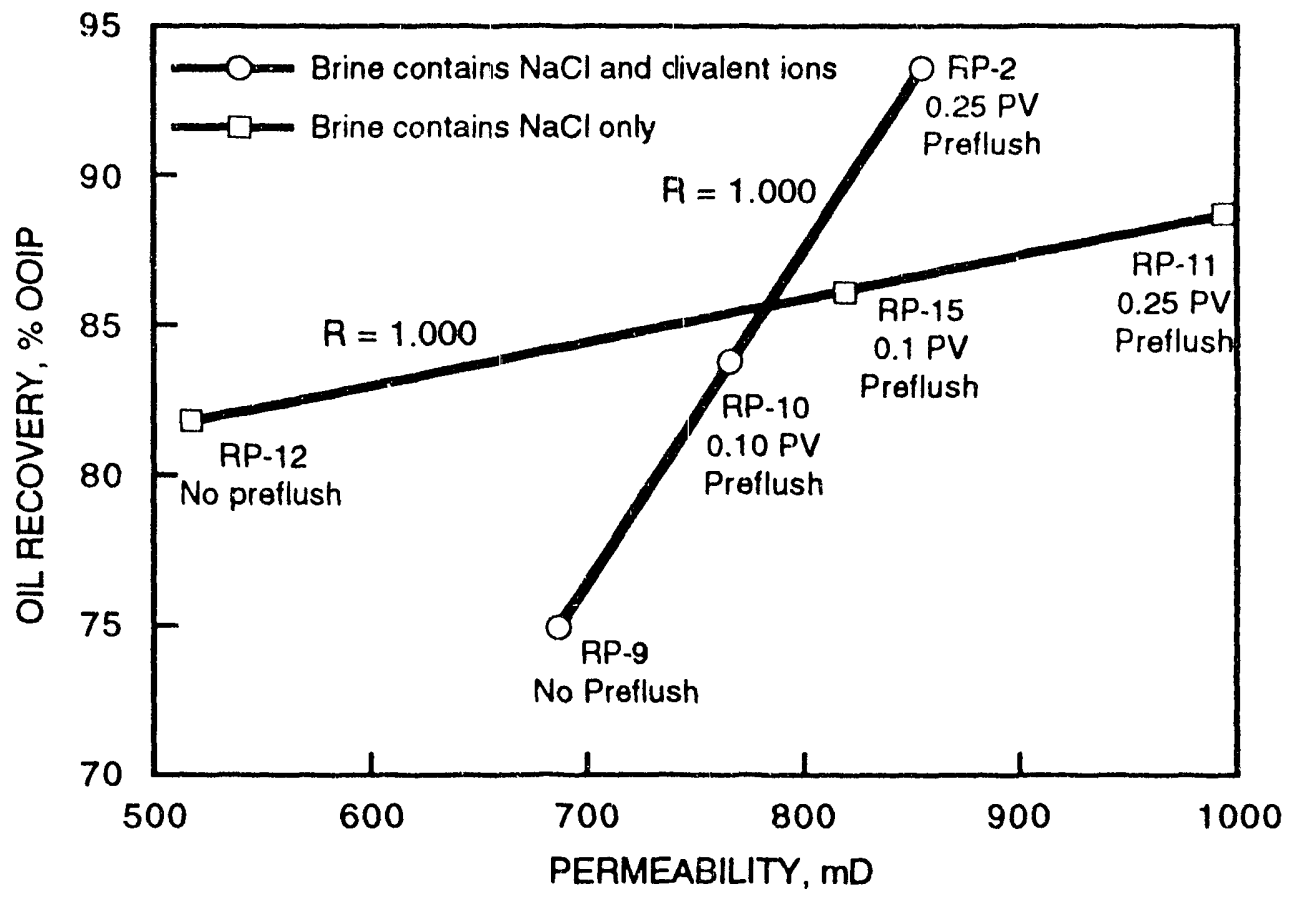

FIGURE 8. - Relationship between oil recovery (waterflood and chemical flood) and alkaline preflush volume. 


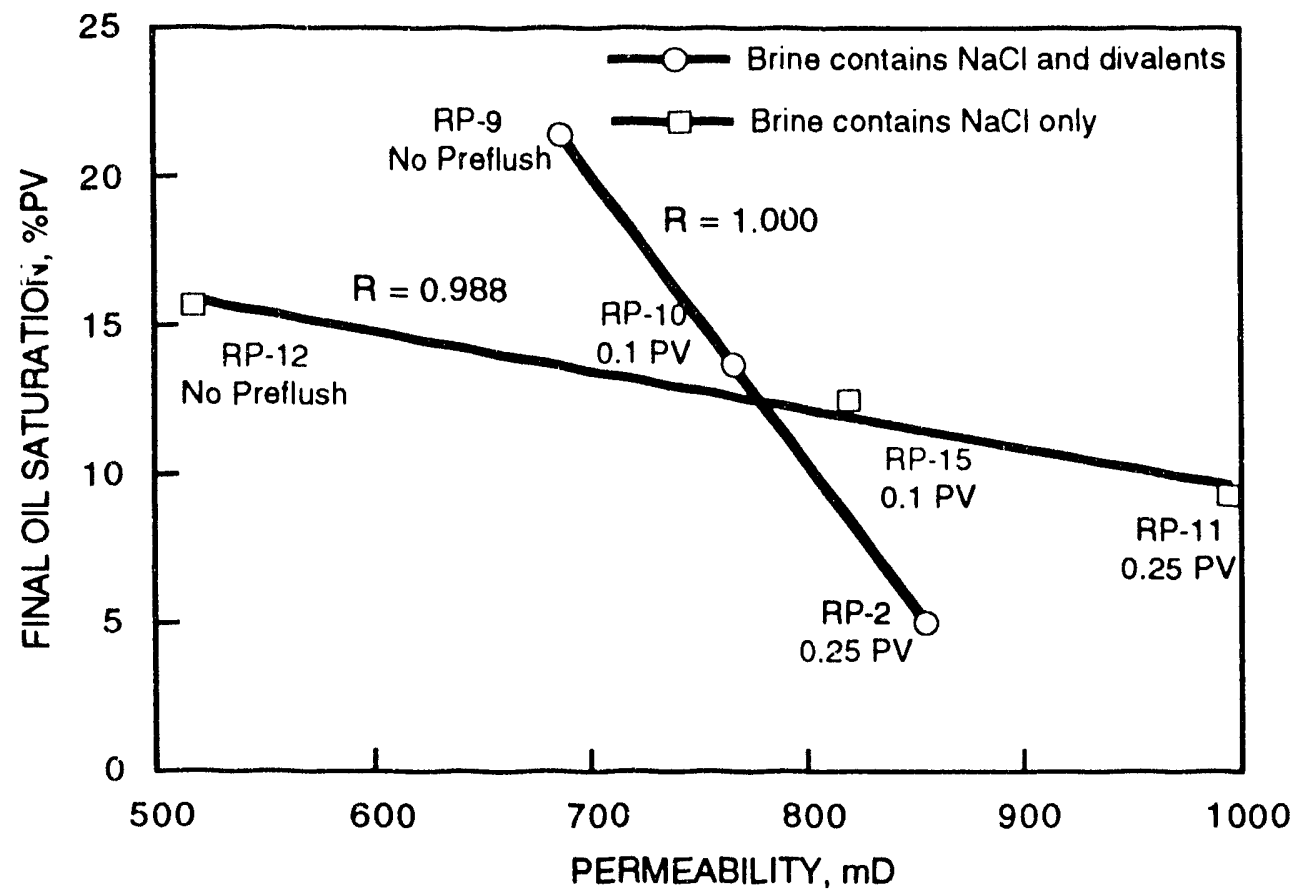

FIGURE 9. - Relationship between final oil saturation and alkaline preflush volume.



FIGURE 1(). - Oil recovery for corefloods conducted with $0.25 \mathrm{PV}$ alkaline preflush. 
APPENDIX A - COREFLOOD EFFLUENT ANALYSIS

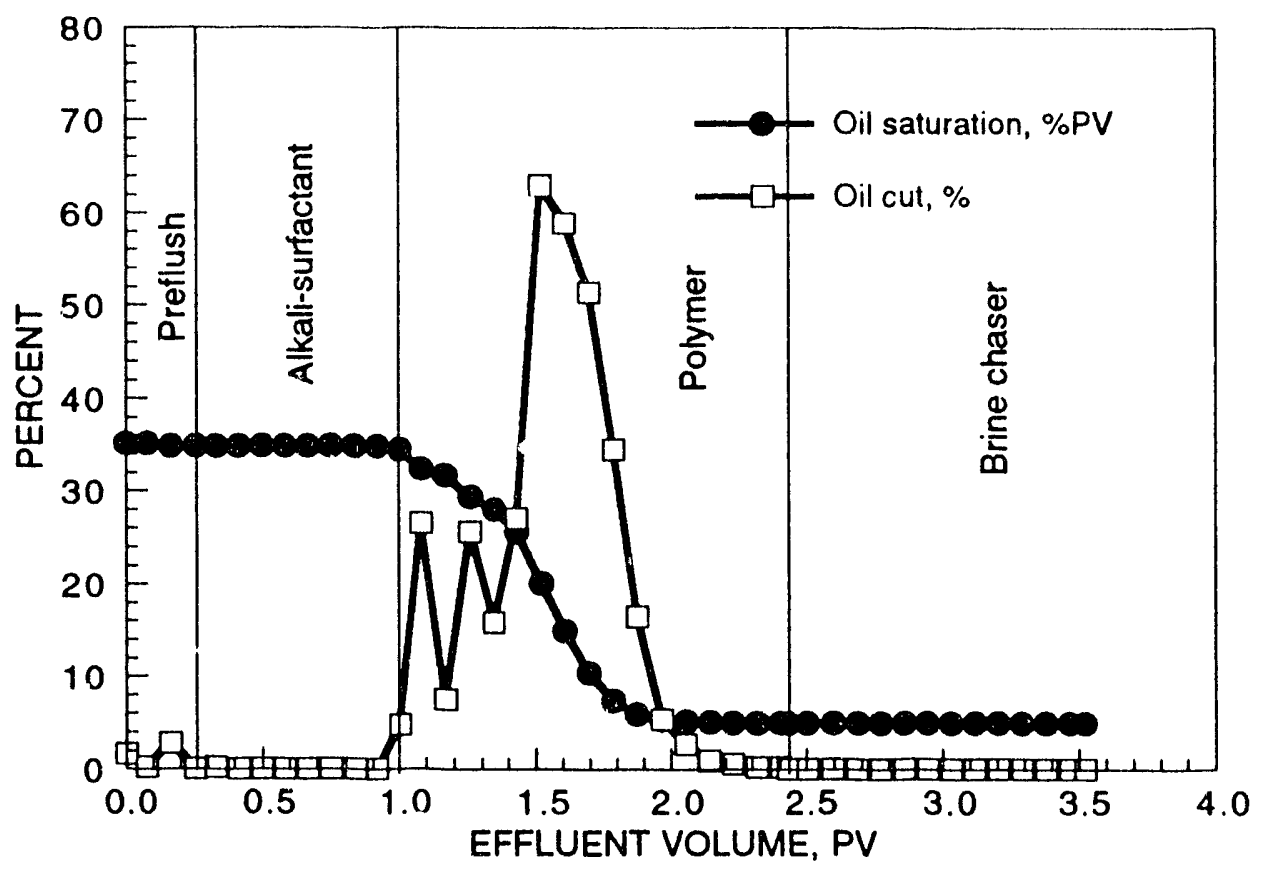

FIGURE A-1. - Coreflood RP-2 oil saturation and effluent oil cut.

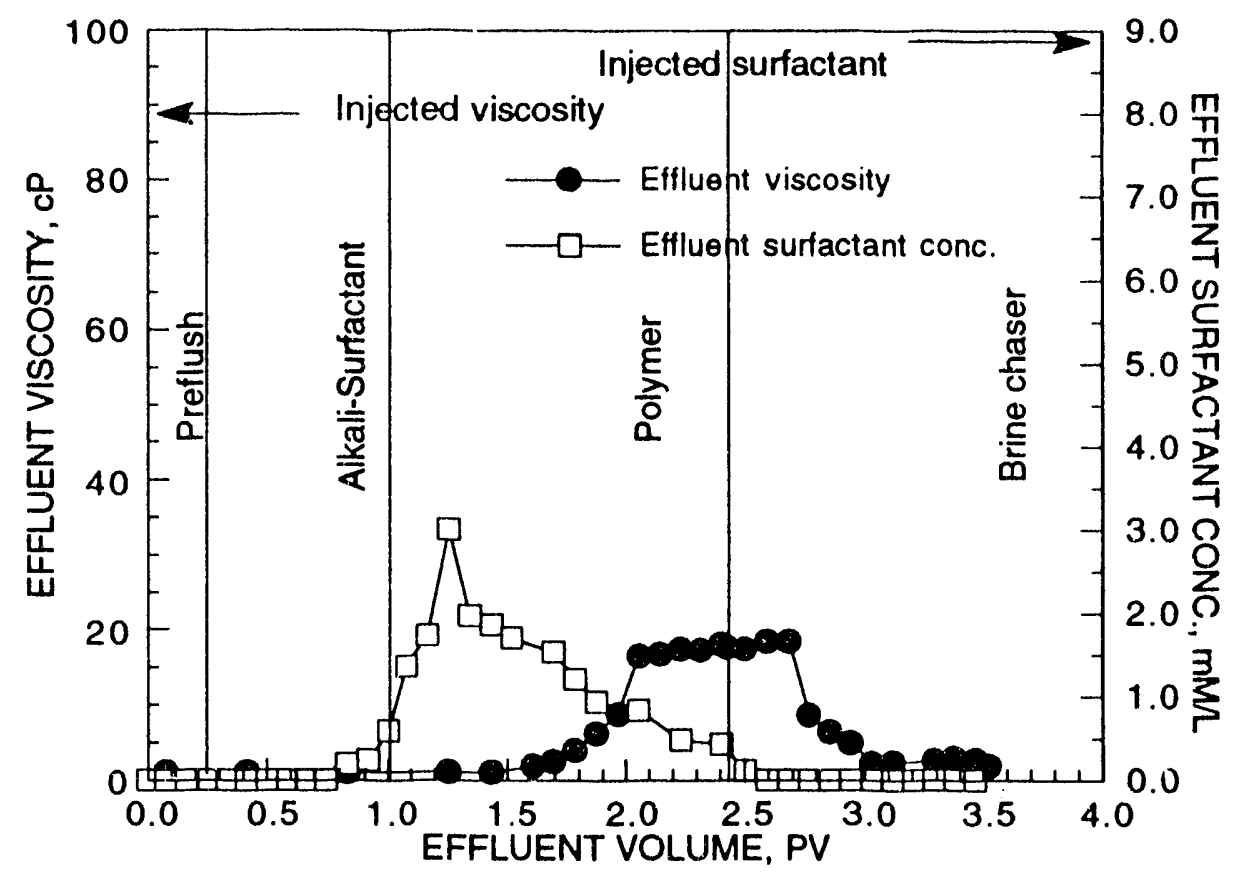

FIGURE A-2. - Coreflood RP-2 effluent viscosity and surfactant analysis. 


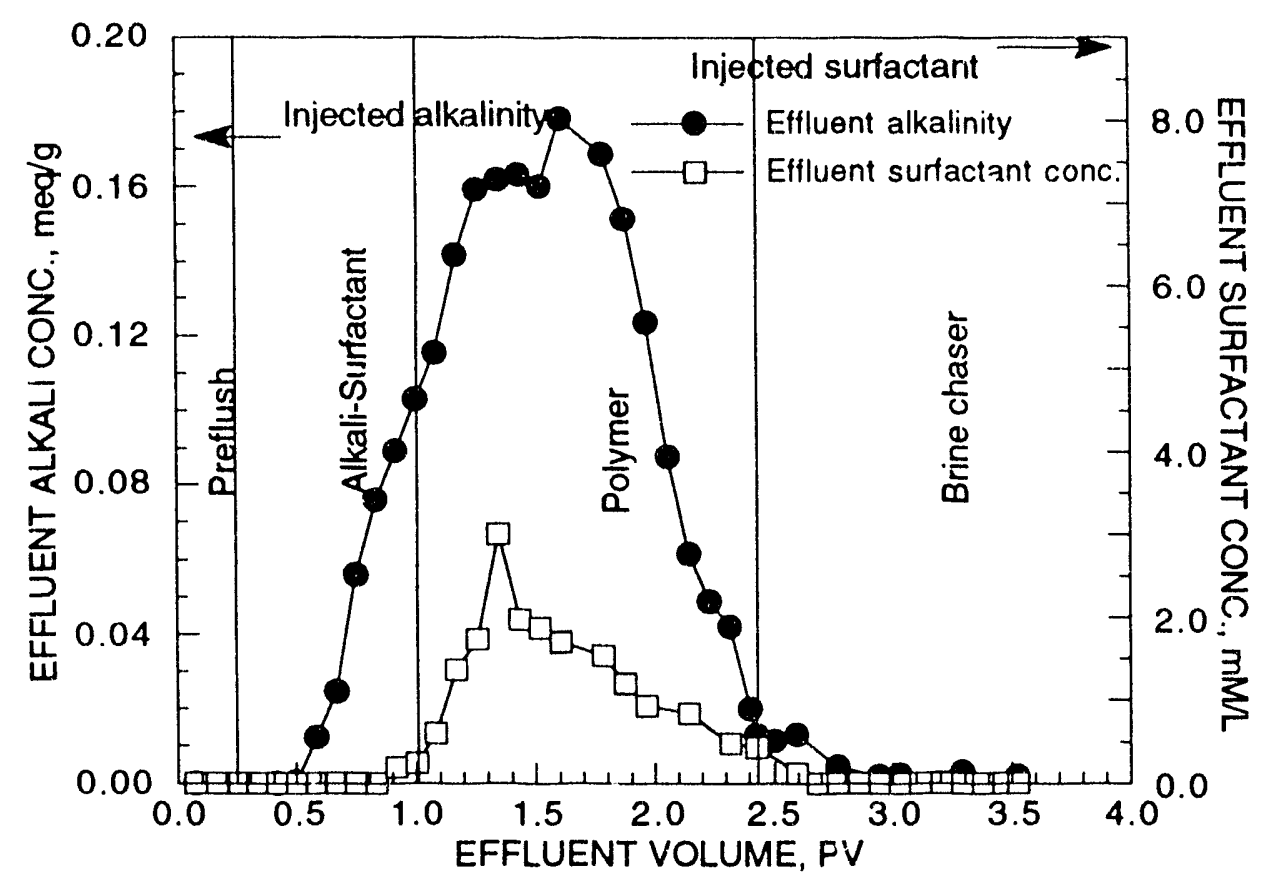

FIGURE A-3. - Coreflood RP-2 effluent alkalinity and surfactant analysis.

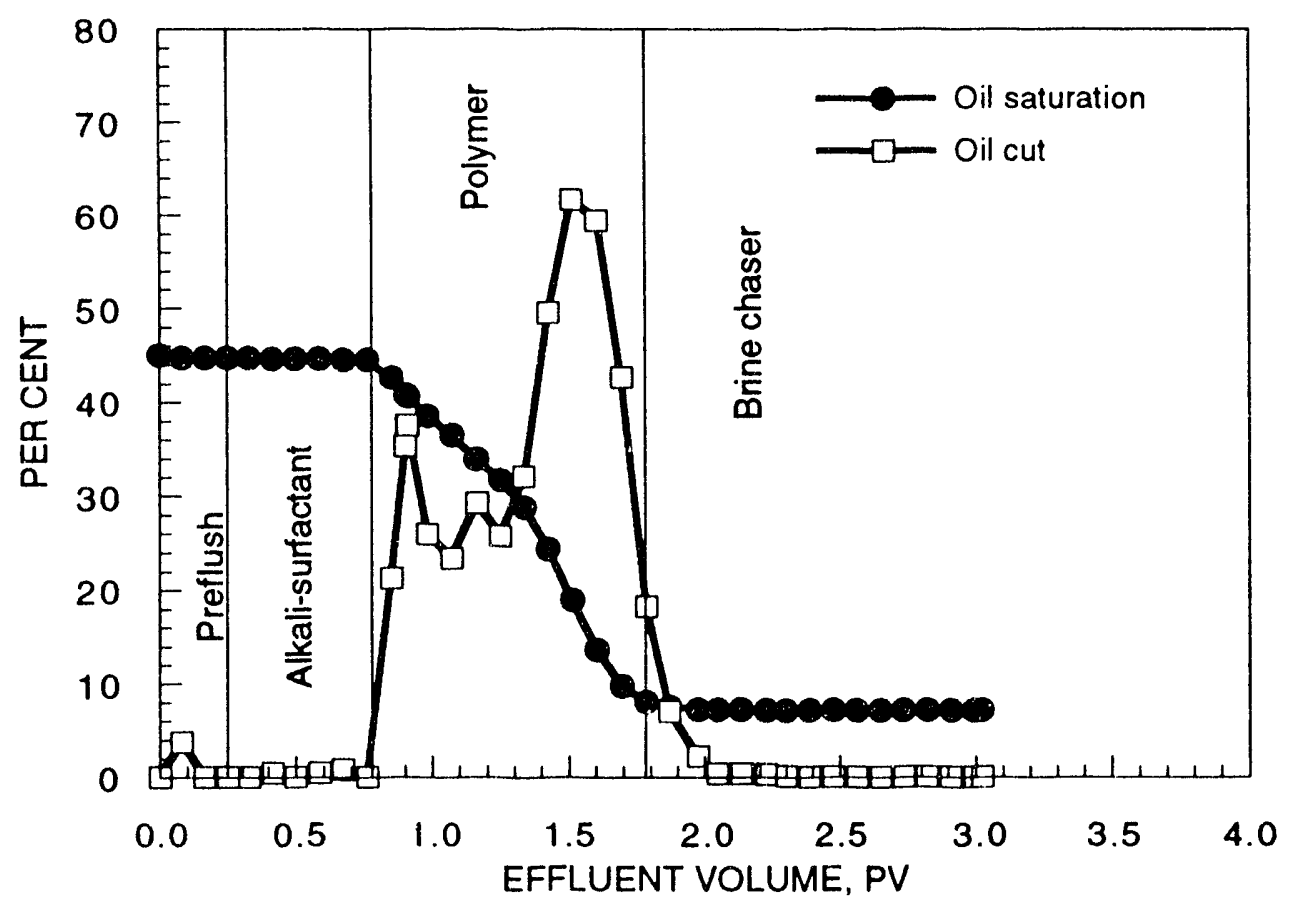

FIGURE A-4. - Coreflood RP-3 oil saturation and effluent oil cut. 


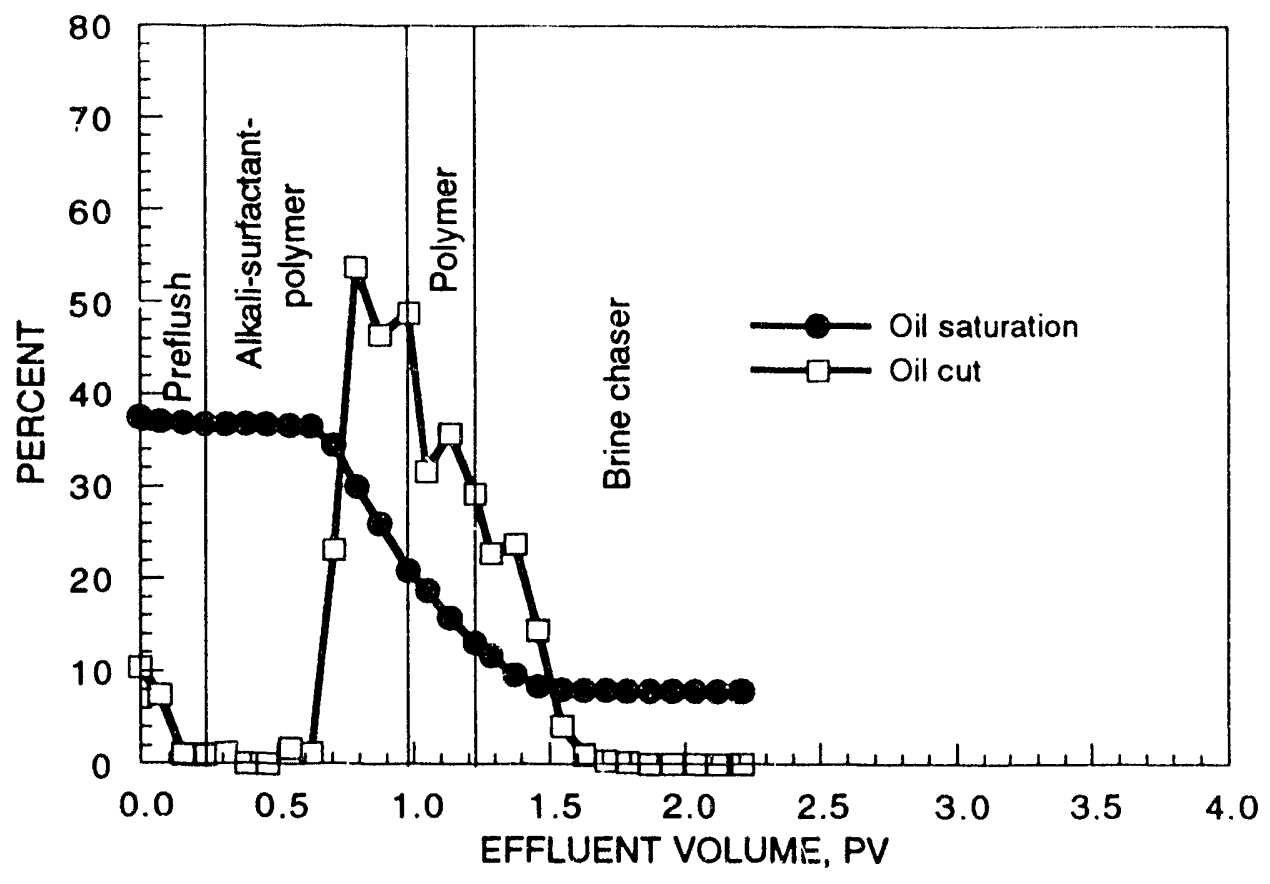

FIGURE A-5. - Coreflood RP-6 oil saturation and effluent oil cut.

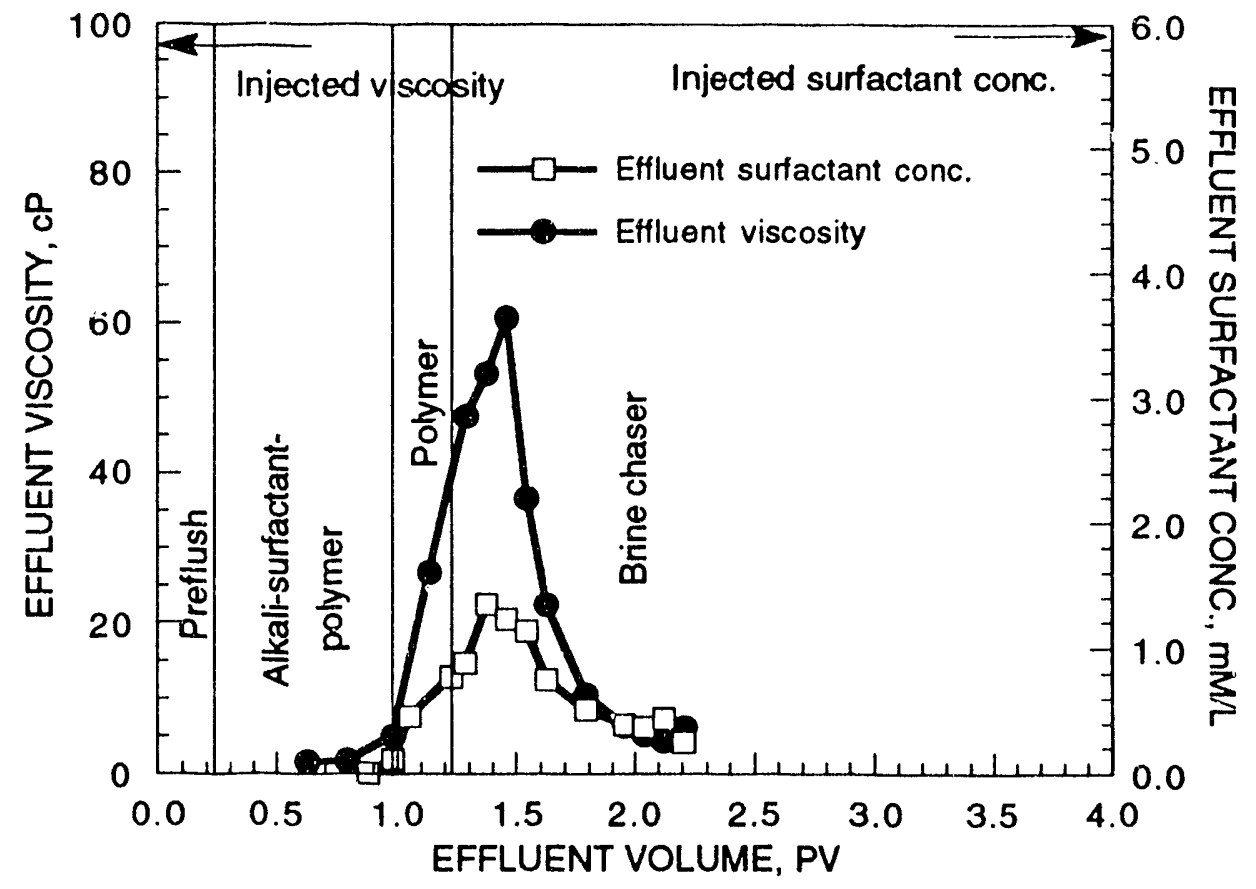

FIGURE A-6. - Coreflood RP-6 effluent viscosity and surfactant analysis. 


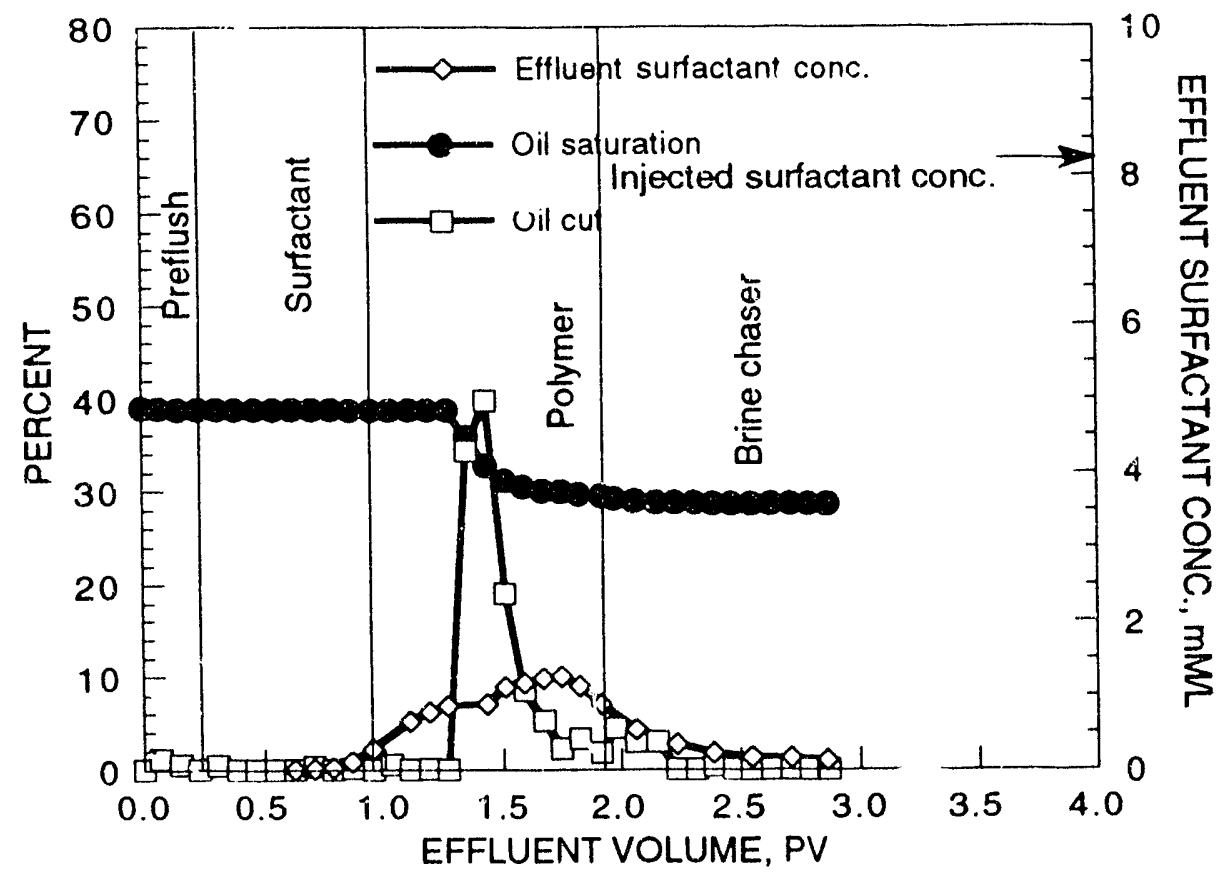

FIGURE A-7. Coreflood RP-7 oil saturation, effluent oil cit, and surfactant analysis.

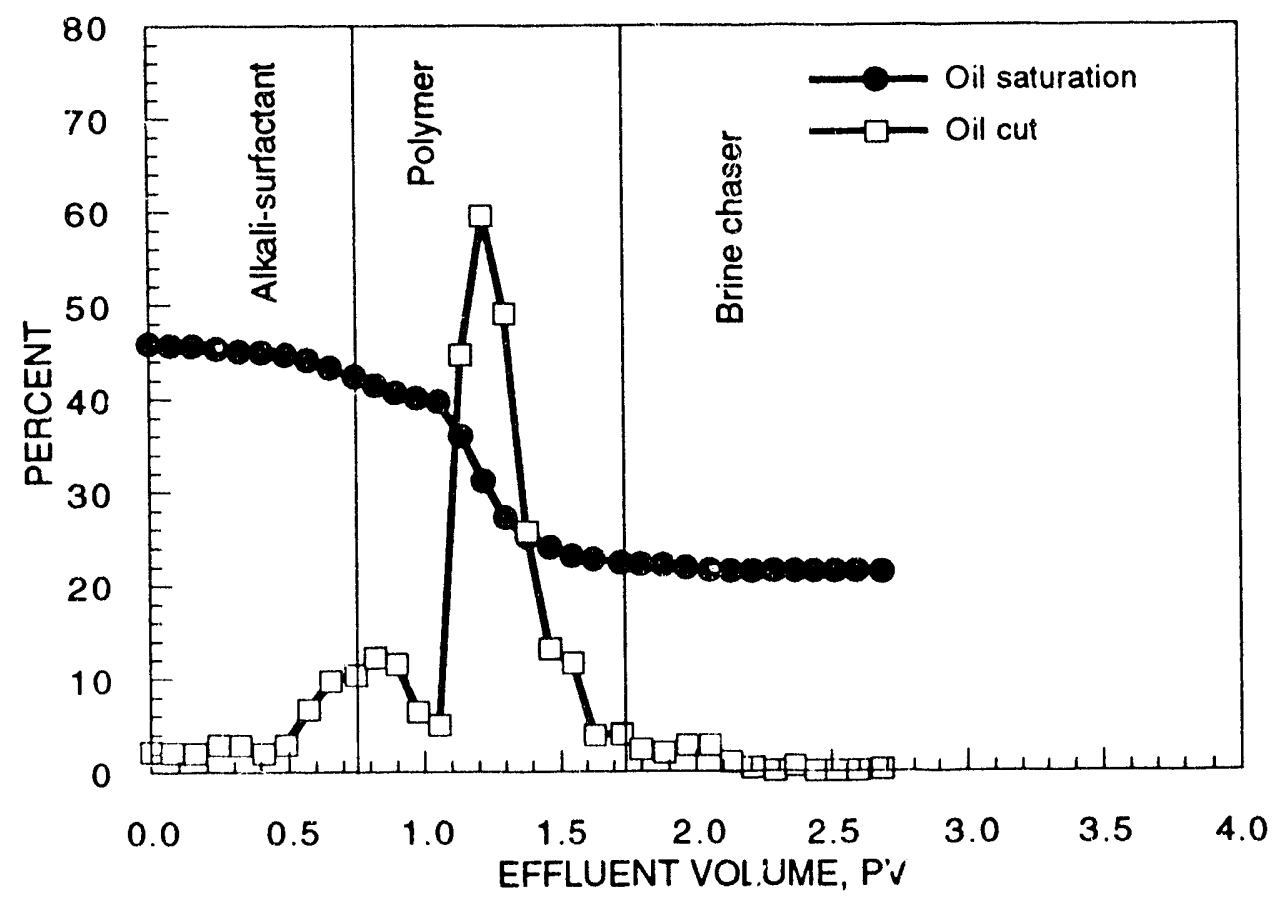

FIGURE A-8. - Coreflood RP-9 oil saturation and effluent oil cut. 


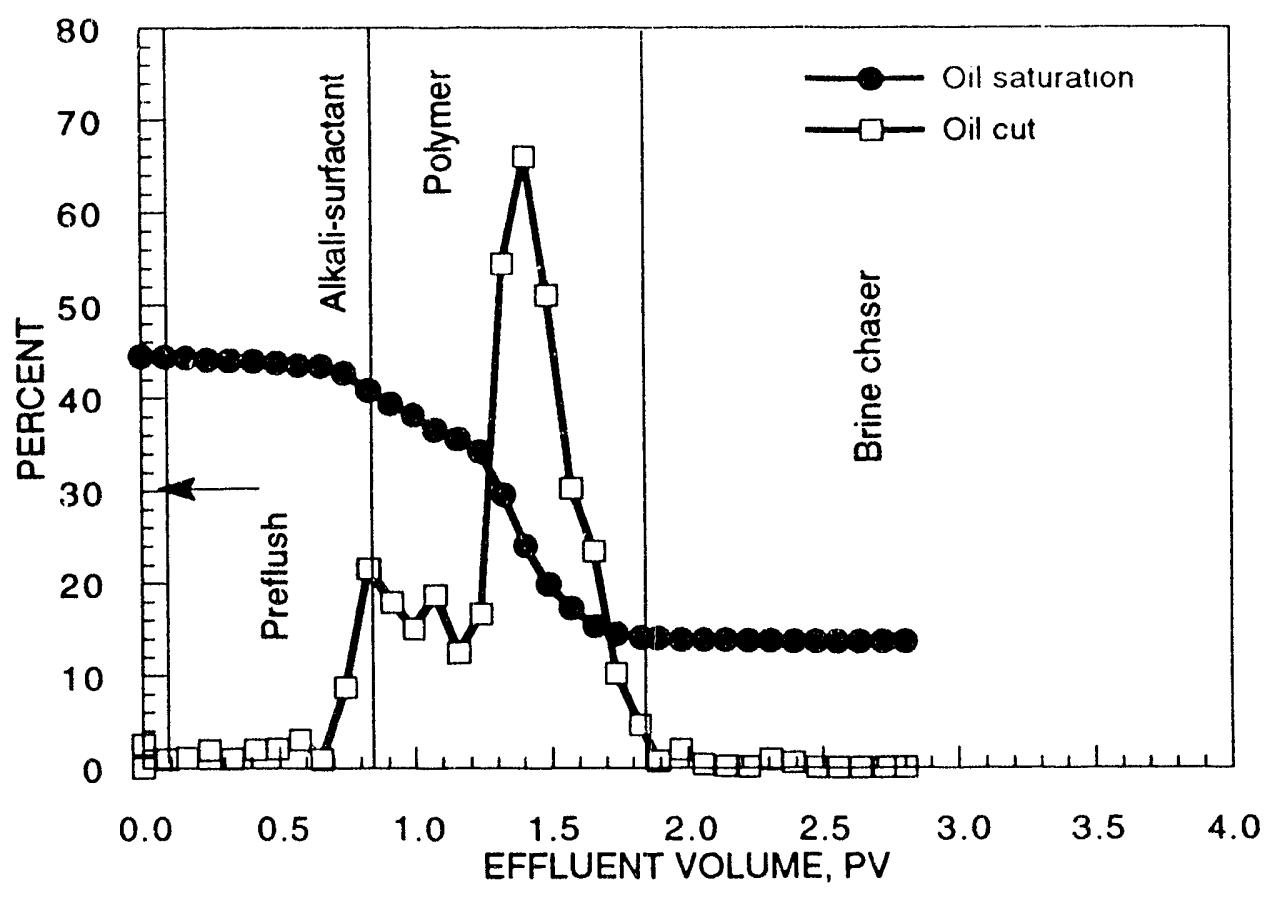

FIGURE A-9. - Coreflood RP-10 oil saturation and effluent oil cut.

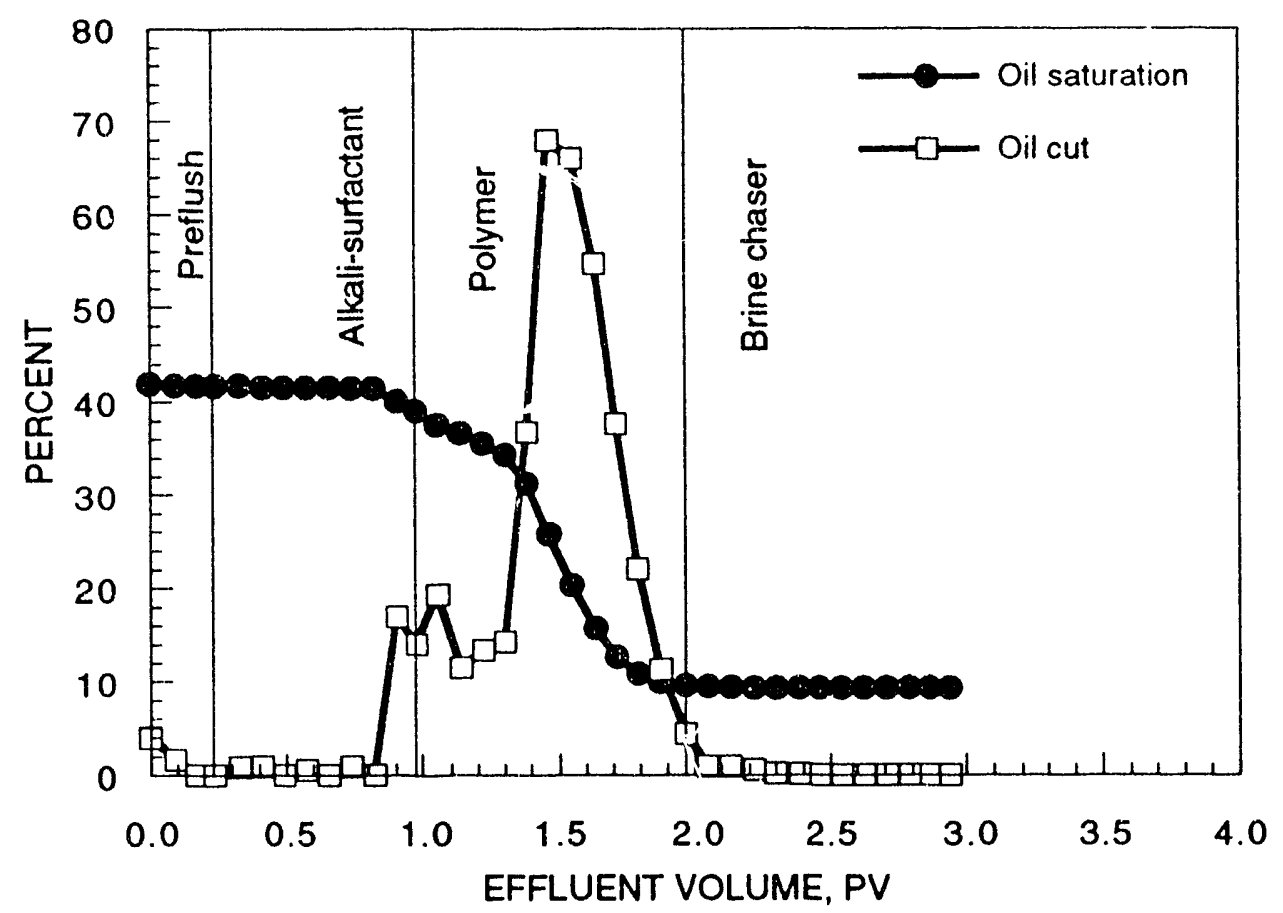

FIGURE A-10. - Coreflood RP-11 oil saturation anci effluent oil cut. 


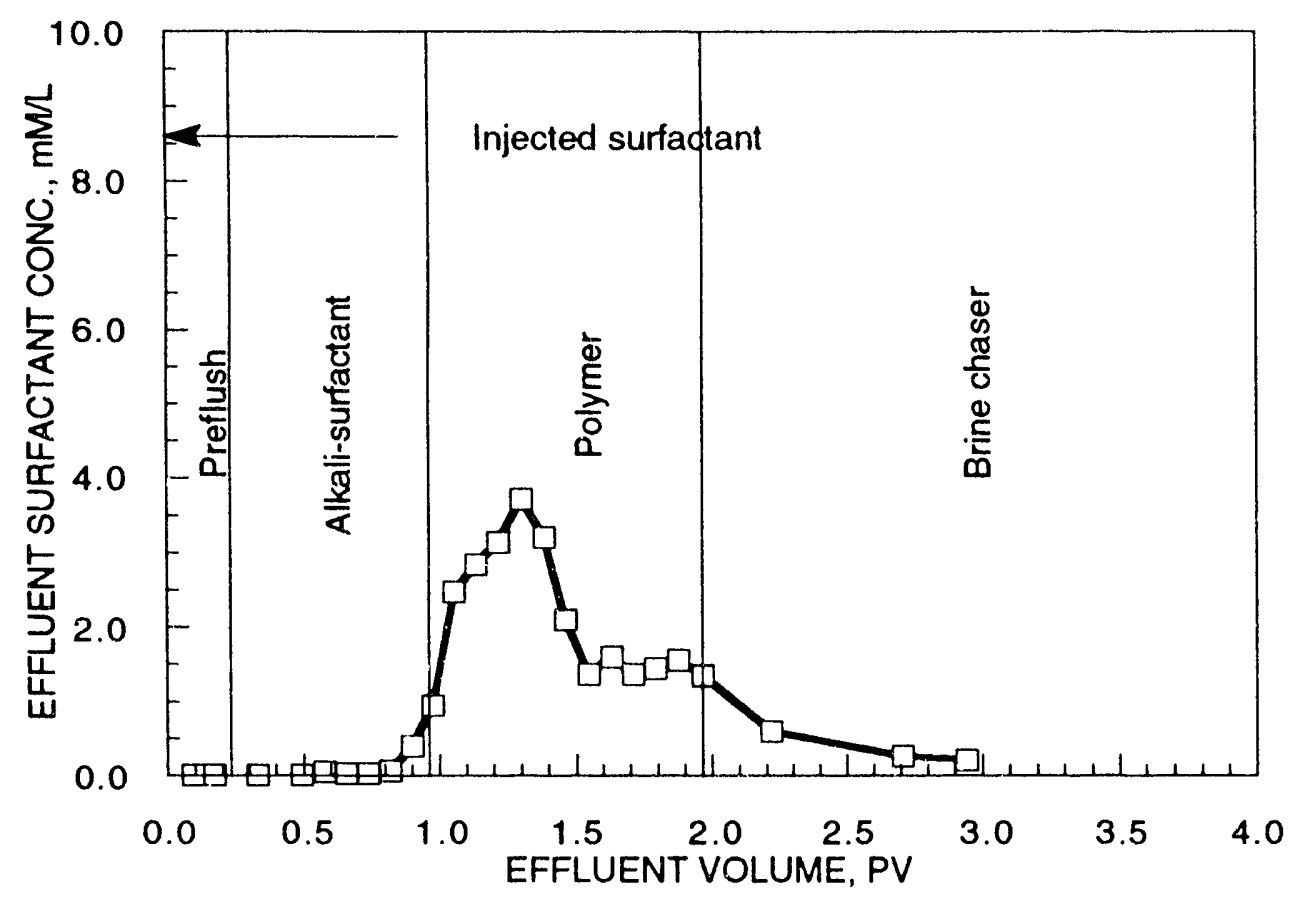

FIGURE A-11. - Coreflood RP-11 effluent surfactant analysis.

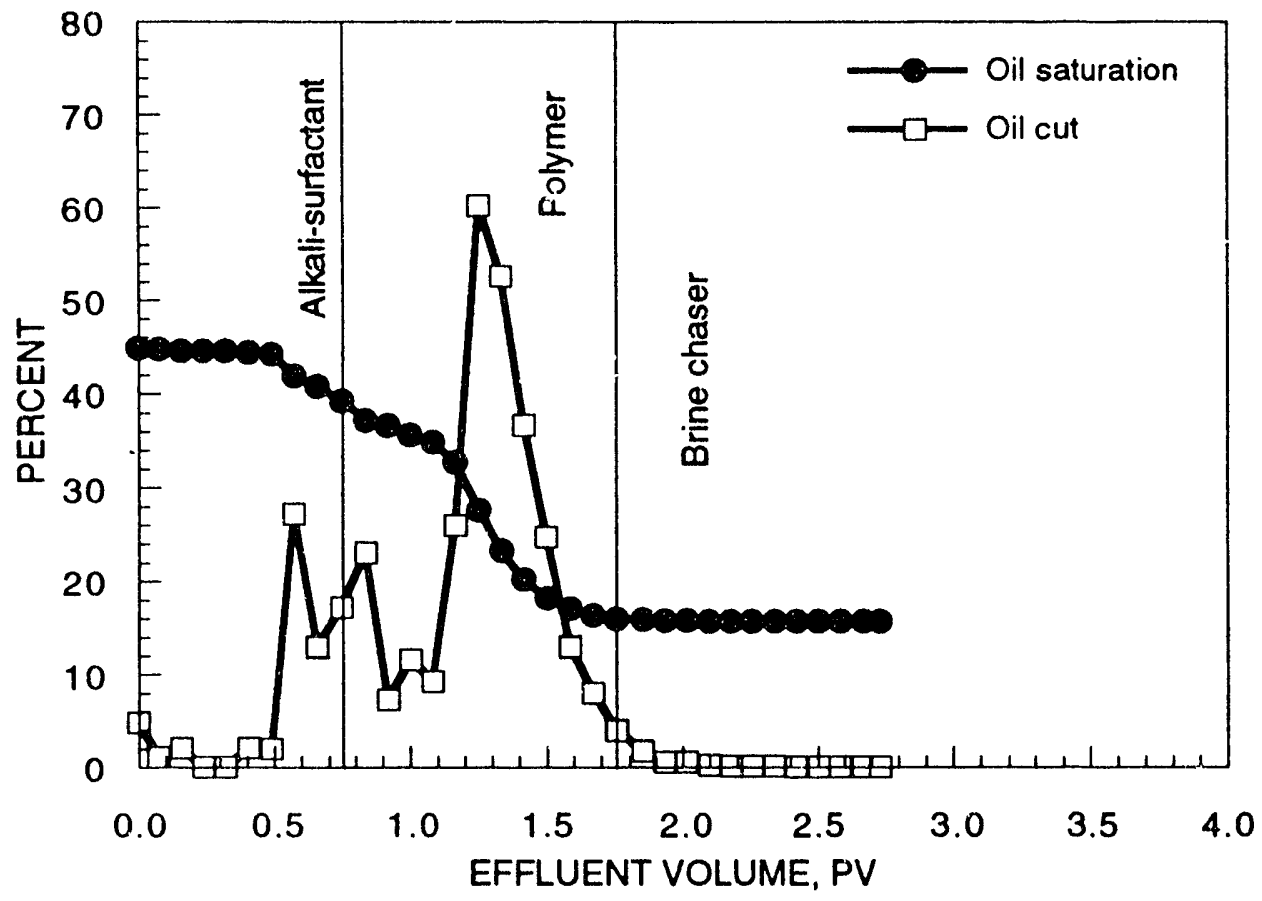

FIGURE A-12. - Coreflood RP-12 oil saturation and effluent oil cut. 


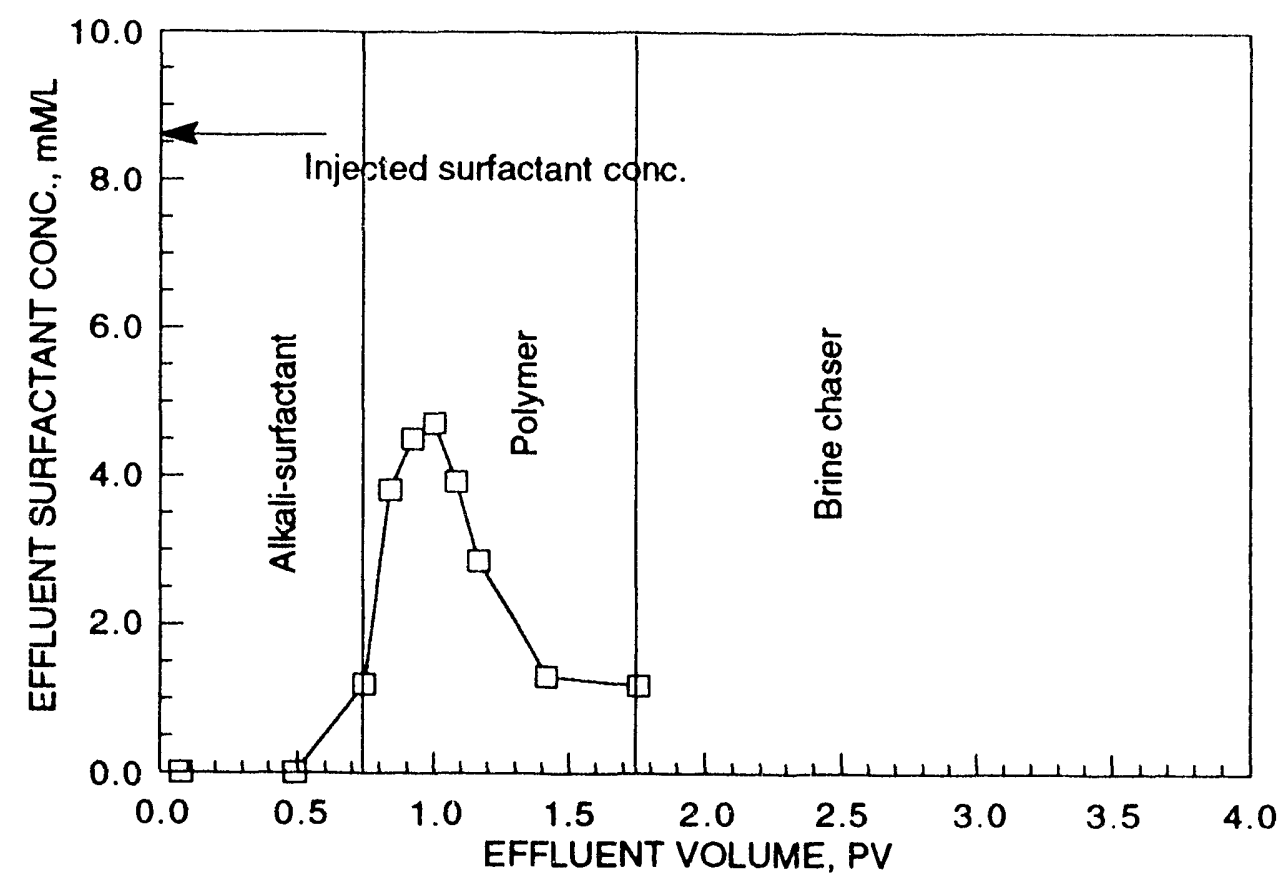

FIGURE A-13. - Coreflood RP-12 effluent surfactant analysis.

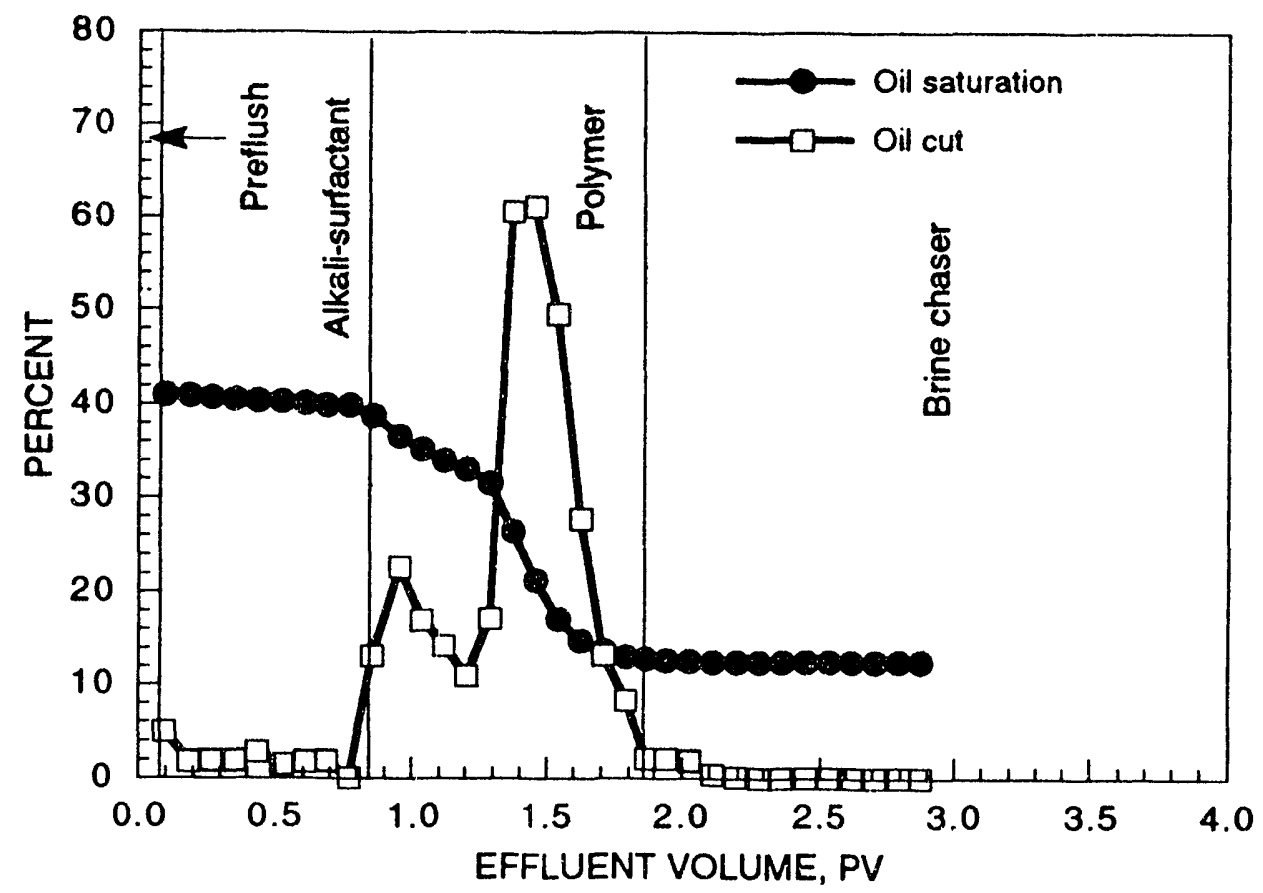

FIGURE A-14. - Coreflood RP-15 oil saturation and effluent oil cut. 


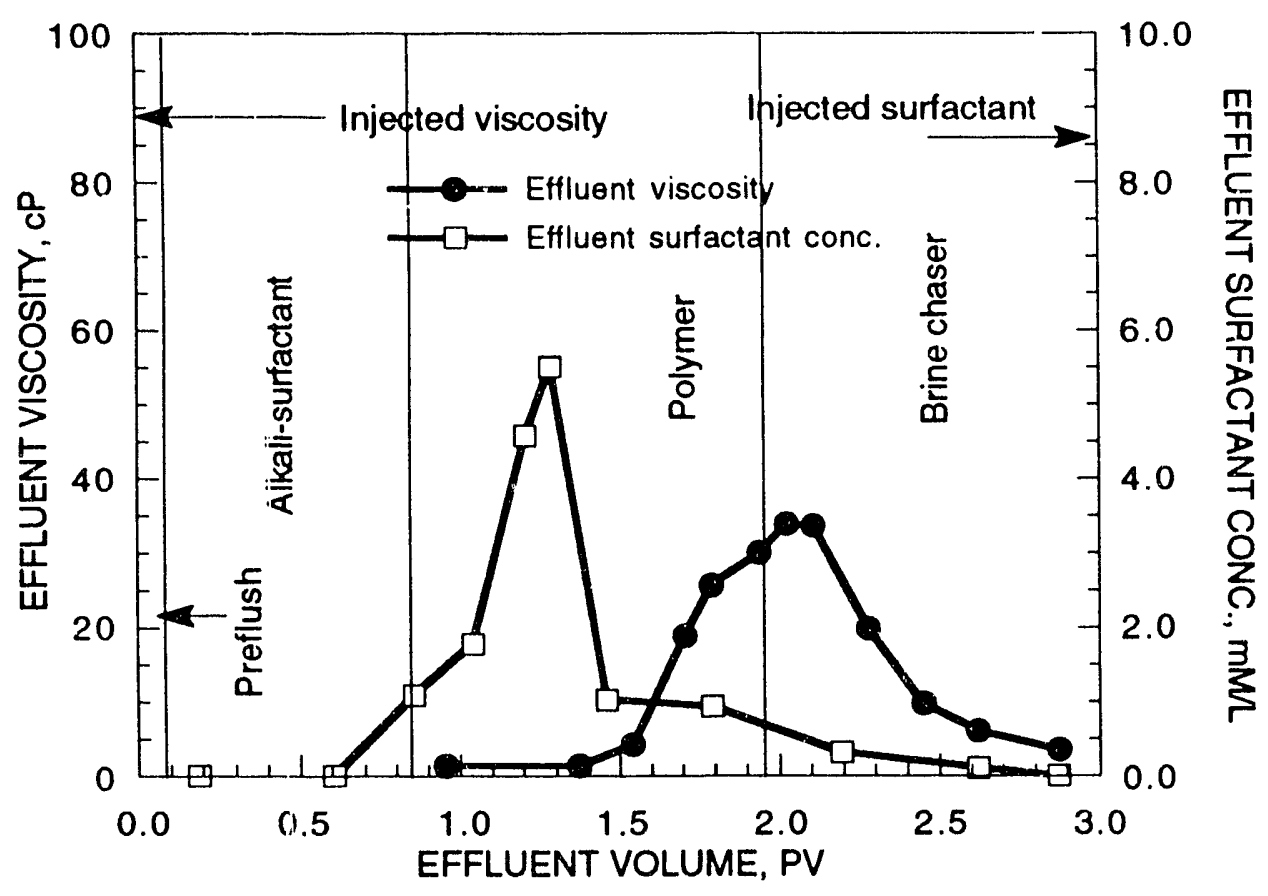

FIGURE A-15. - Coreflood RP-15 effluent viscosity and surfactant analysis.

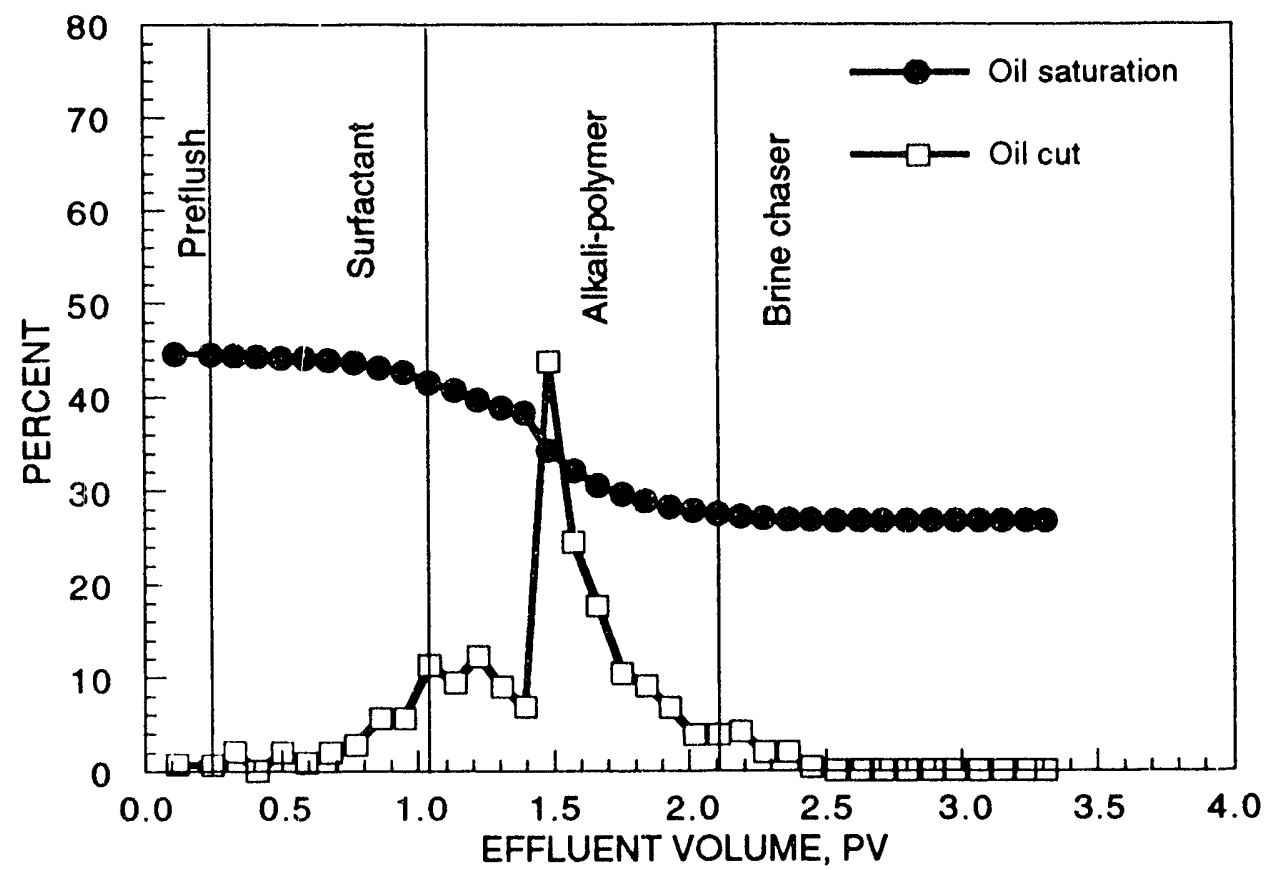

FIGURE A-16. - Coreflood RP-17 oil saturation and effluent oil cut. 


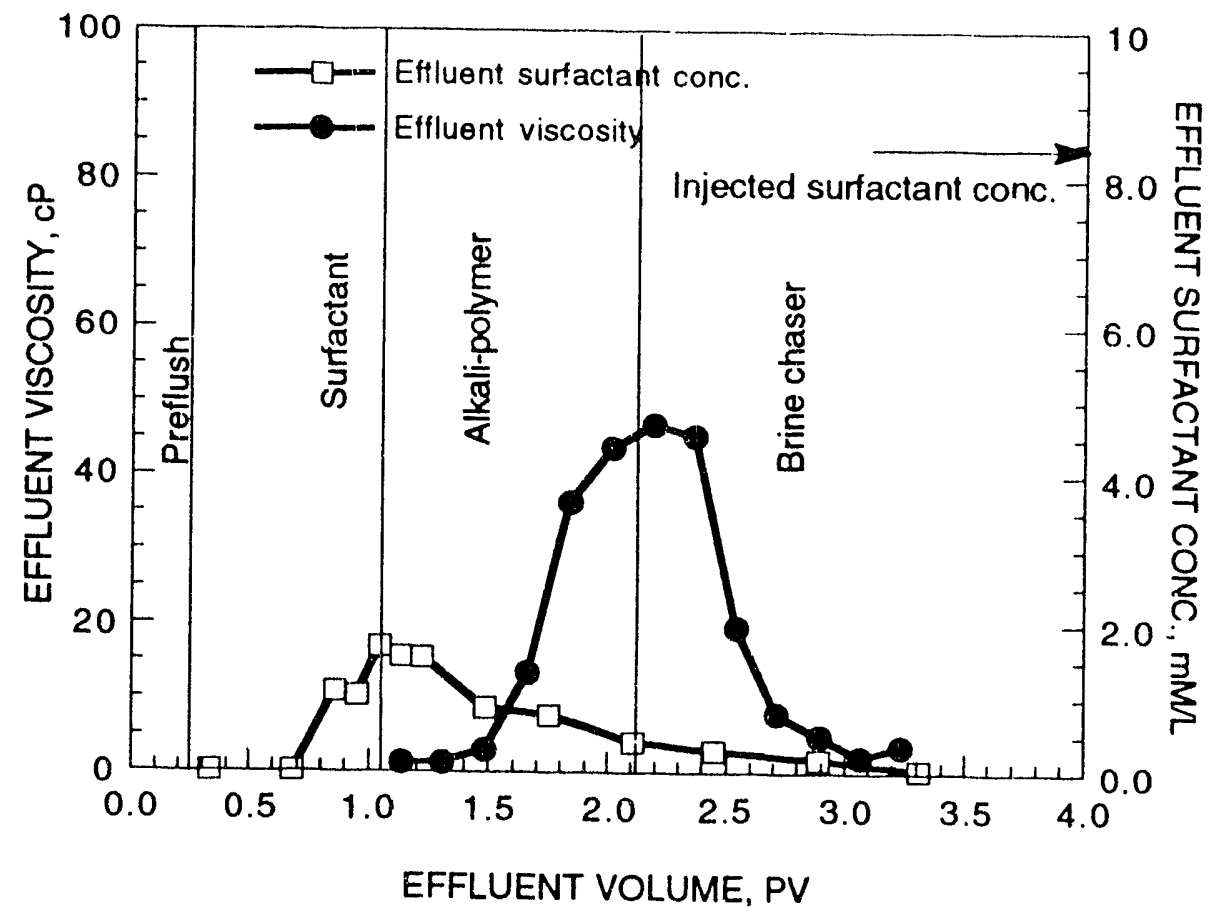

FIGURE A-17. - Coreflood RP-17 effluent viscosity and surfactant analysis. 


